\title{
Tabularia
}

Des sources comptables au service de l'archéologie : essai de reconstruction documentaire de la chapelle dite Saint-Nicolas du château de Falaise (Calvados), $\mathrm{XII}^{\mathrm{e}}-\mathrm{XV}^{\mathrm{e}}$ siècles

Book-keeping sources at the service of archaeology: a tentative documentary reconstruction of the so-called Saint-Nicolas chapel of the Castle of Falaise (Calvados), $12^{\text {th }}-15^{\text {th }}$ centuries

\section{Isabelle Chave}

\section{(2) OpenEdition}

\section{Journals}

Édition électronique

URL : http://journals.openedition.org/tabularia/1219

DOI : $10.4000 /$ tabularia. 1219

ISSN : 1630-7364

Éditeur :

CRAHAM - Centre Michel de Boüard, Presses universitaires de Caen

Référence électronique

Isabelle Chave, «Des sources comptables au service de l'archéologie : essai de reconstruction documentaire de la chapelle dite Saint-Nicolas du château de Falaise (Calvados), XIIe-XVe siècles », Tabularia [En ligne], Les sources comptables, méthodologie, critique et édition, mis en ligne le 14 décembre 2005, consulté le 01 mai 2019. URL : http://journals.openedition.org/tabularia/1219; DOI : 10.4000/tabularia.1219 


\title{
Des sources comptables au service de l'archéologie: essai de reconstruction documentaire de la chapelle dite Saint-Nicolas du château de Falaise (Calvados), $\mathrm{XII}^{\mathrm{e}}-\mathrm{XV}^{\mathrm{e}}$ siècles
}

\section{Book-keeping sources at the service of archaeology: a tentative documentary reconstruction of the so-called Saint-Nicolas chapel of the Castle of Falaise (Calvados), $12^{\text {th }}-15^{\text {th }}$ centuries}

\author{
Isabelle CHAVE ${ }^{1}$ \\ Archives départementales des Vosges \\ ichave@cg88.fr \\ Résumé: \\ Détruit en 1944, l'édifice de culte implanté dans la cour du château de Falaise (Calvados) \\ est mal connu. Clairement énoncés, les problèmes typologiques posés par les vestiges, dégagés \\ lors d'un sondage archéologique en 1986, n'avaient pu bénéficier de l'éclairage de certaines \\ sources. Des pièces comptables médiévales, des textes modernes et un dossier iconographi- \\ que riche, de 1750 à 1880 environ, permettent de réinterpréter ces constats et, tout à la fois, \\ de préciser le statut de la chapelle castrale Saint-Nicolas, desservie au Moyen Âge par le \\ clergé de l'abbaye Saint-Jean de Falaise.
}

Mots-clés: Architecture religieuse, période romane, ducs de Normandie, château de Falaise, abbaye Saint-Jean de Falaise.

\begin{abstract}
:
Destroyed in 1944, the sanctuary built in the yard of the Castle of Falaise (Calvados) is not well known. Clearly stated, the typological problems raised by the remains dug up during an archaeological boring investigation have nevertheless been poorly explained. Medieval accouting vouchers, modern texts and a rich collection of pictures dating from about 1750 to 1880, enable a re-interpretation of these observations and a reassessment of the status of the Castle Chapel of Saint-Nicolas which was served in the Middle Ages by the clergy of the Saint-Jean Abbey in Falaise.

Keywords: Sacred architecture, Romanesque period, Dukes of Normandy, Castle of Falaise, Abbey Saint-Jean of Falaise.
\end{abstract}

1. À Bruno Fajal et Jean-Claude Fossey (CRAHM - UMR 6577) vont mes sincères remerciements pour avoir réalisé, sur la base de dessins originaux, les plans restitutifs de la chapelle castrale illustrant cet article. 
La chapelle Saint-Nicolas du château de Falaise (Calvados), citée pour la première fois en 1200 comme dépendance de l'abbaye Saint-Jean de Falaise, elle-même fondée en 1127, complétait, par son statut d'église paroissiale, le réseau des églises de la ville, de fondation bien antérieure ${ }^{2}$. Les premières mentions de l'existence d'un castrum à Falaise remontent aux années 960-10273. La construction de la chapelle castrale s'inscrit dans le considérable développement du site au XII ${ }^{e}$ siècle, comprenant notamment l'édification d'une ample tour-résidence au point le plus élevé, pourvue d'une chapelle privée.

Totalement détruits en élévation par les bombardements de 1944, les vestiges de la chapelle Saint-Nicolas implantée dans la cour du château bénéficient toutefois d'un bon dossier iconographique entre le milieu du XVIII ${ }^{\mathrm{e}}$ siècle et la fin du XIX ${ }^{\mathrm{e}}$ siècle. Les sources documentaires médiévales et modernes apportent, par ailleurs, sur l'évolution architecturale de la chapelle de la basse-cour, un éclairage nouveau, qui autorise à reconsidérer les constats dressés lors d'un sondage archéologique mené en 1985-1986

Aujourd'hui dispersées entre plusieurs lieux de conservation ${ }^{5}$, les pièces comptables médiévales relatives à la chapelle Saint-Nicolas du château de Falaise offrent un éventail typologique représentatif de la production documentaire des XIII ${ }^{\mathrm{e}}$ $\mathrm{XV}^{\mathrm{e}}$ siècles, dans le contexte des chantiers domaniaux menés par l'administration royale déléguée. À l'origine d'une campagne de travaux, se trouve le plus souvent une visite de routine des bâtiments domaniaux (château, halles, moulins, cohues, etc.), menée par le maître des œuvres territorialement compétent, lorsqu'il existe ${ }^{6}$; sinon, par un membre de l'administration locale : capitaine du château, châtelain ou vicomte de Falaise. Requêtes, demandes, ordres, devis, comptes rendus d'adjudication, marchés de travaux, ordres de paiement, certificats de réception, quittances, déclarations ou rôles de travaux, comptes du vicomte et receveur, suivent les différentes étapes de la gestion administrative des travaux engagés, de la prise de décision à la réception de chantier. Les travaux sont menés à journées, à tâche, par taxation, ou comportent un marché de gré à gré ou à rabais. L'enregistrement de la hauteur du

2. Guibray au VIIIe siècle, La Trinité vers 840, Saint-Christophe-et-Saint-Jacques, vers 940, devenue Saint-Gervais, consacrée en 1124 [German, p. 28, p. 46].

3. Chronique de Robert de Torigni, éd. Léopold Delisle, Rouen, 1872, I, p. 164, 196. GuILlaUME DE JUMIĖGES, Gesta Normannorum ducum, éd. Jean MARX, Rouen/Paris, 1914, VI-2, p. 98.

4. COUANON, 1986.

5. BnF (ms fr., nouv. acq. fr., pièces originales); B. L. (Add. Ch.) ; Caen, Arch. dép. Calvados (collection Danquin).

6. Citons pour le château de Falaise, Guillaume Roussel, charpentier du roi, vers 1350; Robert/Robin Delaunoy, maître des œuvres de charpenterie au château (1397-1398), maître des ouvrages du château (1398), maître des œuvres du roi en la vicomté de Falaise (1403-1416), maître et visiteur des œuvres (1407-1408); Jean du Moustier, maître des œuvres du roi en la vicomté de Falaise (1423-1437); Guillaume Le H(e) urteur, maître des œuvres du roi en la vicomté de Falaise (1441-1448); Pierrel Perrin Thomine, maître des œuvres du roi à Falaise (1453-1455), puis en la vicomté de Falaise (14561459) ; Colin Hache, maître des œuvres et réparations du roi en la vicomté de Falaise (1481-1482) [CHAVE, 1999, vol. III]. 
débours, au titre de la comptabilité du terme annuel correspondant, est fait $a$ posteriori $^{7}$. Michel Nortier et Robert-Henri Bautier ont explicité déjà le mode de création, les avatars de la conservation et l'intérêt de la comptabilité médiévale au plan de l'histoire de l'art ${ }^{8}$, qui vit à la fin du Moyen Âge une véritable « révolution» ${ }^{9}$.

\section{Destructions et modifications modernes}

\section{La destruction de la nef en 1772}

Sur le plus ancien document graphique conservé témoignant de l'organisation de la chapelle - un plan levé par l'atelier de Jean Rodolphe Perronet, dans les années 1744-1747 ${ }^{10}$-, l'édifice de culte, correctement orienté, présente deux parties : la nef, à l'ouest, de plan rectangulaire ; le chœur, à l'est, de plan rectangulaire plus réduit, équivalent au tiers de la surface de la nef. La comparaison de ce document avec des plans de 1792-1793 [fig. 1] laisse supposer que l'édifice de culte a été victime dans la seconde moitié du XVIII ${ }^{\mathrm{e}}$ siècle, d'une destruction radicale de la nef à l'ouest. Au début des années 1790 , celle-ci a laissé place à un terrain régulièrement planté d'arbres, limité au sud par un muret orienté est-ouest. Cette destruction majeure est bien documentée : le 8 août 1772, répondant à une requête du comte d'Aubigny, lieutenant général de ses armées et gouverneur de la ville et du château de Falaise, le roi Louis XVI autorisait à détruire la nef, fermer l'entrée du chœur, restaurer le chœur "en tel état que l'on puisse y celebrer decemment la messe et avec sureté» grâce à ces matériaux de démolition et à y transporter les fonts baptismaux ${ }^{11}$. Cette demande avait été justifiée par l'état de délabrement général de l'édifice (couverture détruite, murs quasi-ruinés, atteinte à la sécurité du célébrant et des fidèles) ${ }^{12}$ et par le coût

7. Pour une synthèse sur la conduite des campagnes de travaux sur les chantiers domaniaux en Normandie méridionale, voir CHAVE, Isabelle, Les châteaux de l'apanage d'Alençon, Alençon, Société historique et archéologique de l'Orne (coll. Mémoires et documents, n 4), 2003, p. 309-325.

8. NORTIER, Michel, "Le sort des archives de la Chambre des comptes", Bibliothèque de l'École des Chartes, 1965, t. 123; BAUTIER, Robert-Henri, «Les sources documentaires de l'histoire de l'art médiéval», in Artistes, artisans et production artistique au Moyen Âge [actes de colloque, Rennes, 1983], Xavier Barral i Altet (dir.), Paris, Picard, 1986, t. I, p. 15-27.

9. Voir la présentation liminaire d'Olivier GUYOTJEANNIN « La révolution comptable des XIII ${ }^{\mathrm{e}}-\mathrm{XV}^{\mathrm{e}}$ siècles ", in Le financement de la construction en France aux XIII ${ }^{e}-X V I^{e}$ siècles [actes de colloque, Vincennes, 27-29 juin 2002], Jean CHAPELOT (dir.), à par. en 2006.

10. Arch. nat., $\mathrm{F}^{14} 8451$, fol. 28.

11. Alençon, Arch. dép. Orne, C 6, le prieur Charles Alliot à l'intendant de la généralité d'Alençon (17 juin 1772). Caen, Arch. dép. Calvados, H 4166, édit royal (8 août 1772, copie collationnée du 16 septembre 1772). La destruction fut engagée avec l'accord du prieur de l'abbaye Saint-Jean de Falaise et de l'intendant d'Alençon.

12. Le prieur de Saint-Jean s'en défendait avec amertume en juin 1772 [Alençon, Arch. dép. Orne, C 6, déjà cité: "Il est vrai aussi que cette chapelle est dans un tres mauvais état parce que, comme il ne nous est fait qu'une mince redevance sur le domaine du roy pour la desservir, nous ne sommes pas dans le cas des gros décimateurs qui doivent entretenir le chœur et le chancel de leur église»]. 
excessif d'une restauration globale, pour un nombre réduit de fidèles ${ }^{13}$. Recueillant le mobilier liturgique en place, le chœur quadrangulaire servit, pour vingt ans encore, de chapelle du château, ainsi qualifiée jusqu'à sa disparition en 1944.

La connaissance de cette destruction partielle est essentielle pour interpréter correctement non seulement les sources graphiques des XVIII ${ }^{\mathrm{e}}$ et XIX ${ }^{\mathrm{e}}$ siècles, mais surtout les vestiges mis au jour en 1985-1986. Pour avoir été clairement énoncés alors, les problèmes typologiques posés par les structures dégagées ont été mal justifiés ${ }^{14}$ : "L'examen des vestiges mis au jour permet dès à présent de retrouver l'architecture de l'édifice, tel qu'il apparaisait au XIX ${ }^{e}$ siècle; le plan d'ensemble n'ayant très certainement pas subi beaucoup de modifications depuis le XII siècle». "Le bâtiment, de dimensions modestes (11,90 x 7,60 m hors contreforts) s'apparente mal aux chapelles castrales de tradition romane construites à l'intérieur des enceintes de cette époque: nef à deux travées, chœur plat sans transept». "Les murs de la chapelle mis au jour présentent un bâtiment aux dimensions fort modestes. L'éventualité d'une extension vers l'ouest est à envisager. Toutefois, le rapport longueur/largeur semble correct et l'éventualité d'un édifice du XII siècle conservé en l'état jusqu'au XX'e siècle ne doit pas être exclue». Pourtant, l'architecte Danjoy, clairvoyant, avait livré un indice sur son plan de 1891, en intitulant l'édifice mutilé: "chapelle dont il ne reste que le chour ${ }^{15}$.

\section{Les modifications postérieures}

La chapelle Saint-Nicolas était implantée à l'époque médiévale dans un bâti beaucoup plus dense. À la fin des années 1450, des salles et dépendances (cuisine, four et cave) occupaient les abords ${ }^{16}$. Un procès-verbal de 1790 cite une «charterie en hangar, adossée contre la cotiere de la chapelle ${ }^{17}$. L'édifice de 27 x 12 pieds (env. 9 x $4 \mathrm{~m}$ ), couvert de tuiles, est sans doute celui visible sur les plans de 1792-1793, bâti donc entre 1750 et 1790 . Il fut encore étendu en 1813 et conforté, et figure sur les plans de 1829 et 1836. En revanche, un appendice, cité en 1798, adossé au mur nord du chœur ${ }^{18}$, n'apparaît sur aucun des plans modernes, parce que de structure plus légère sans doute. En 1869, Victor Ruprich-Robert signalait encore que ladite chapelle était « entourée de quelques bâtiments sans valeur artistique » ${ }^{19}$.

Lors du projet d'installation des institutions carcérale et pénale au château de Falaise, en 1792, l’idée fut émise d'abriter dans le chœur le siège des séances de la

13. Alençon, Arch. dép. Orne, C 6, le gouverneur d'Aubigny à l'intendant de la généralité d'Alençon (26 mai 1772) : "La partie du caur [sic] est plus que suffisante pour contenir ma famille et mes gens, seuls habitants à l'intérieur du château». La chapelle est jugée trop vaste, mais «la commodité d'avoir une messe chez [s] oi» est soulignée.

14. CouAnON, 1986, p. 75-92.

15. Paris, Médiathèque du patrimoine, Archives de la commission des Monuments historiques, plan 507.

16. Voir annexe $\mathrm{I}, \mathrm{n}^{\circ} 28$.

17. Caen, Arch. dép. Calvados, 386 E dépôt 499 (8 novembre 1790).

18. Ibidem (12 pluviôse an VI/1798).

19. Paris, Méd. du Patrimoine, 81/14/355/1, carton 106, lettre au ministre des Beaux-Arts (15 mai 1869). Méd. du Patrimoine, Archives de la commission des Monuments historiques, 25 505/22. 
Police conventionnelle. Des travaux de réfection, menés en 1798, ont visé la couverture de tuiles du chœur et la maçonnerie du mur nord, dont quelques assises ont été reliaisonnées au mortier de chaux et de sable. «Vu que cette chapelle ne peut être employée que comme magasin ", les pavés cassés du sol du chœur, fait, d'après les constats des fouilles de 1985-1986, de dalles de calcaire de taille irrégulière récupérées dans les églises de la région, de fragments de pierres tombales du XVIII ${ }^{\mathrm{e}}$ siècle ou de plaques de dédicace ${ }^{20}$, ne furent pas remplacés, non plus que les vitres des croisées, alors en grande partie brisées ${ }^{21}$. Lors de la construction du collège dans l'enceinte castrale en 1803, la charpente et la toiture du chœur de la chapelle médiévale furent à nouveau reprises, avec des tuiles fixées au mortier de chaux et de sable ${ }^{22}$. L'édifice médiéval était couvert d'une voûte cintrée; mais, en 1805, il est signalé qu'elle est dissimulée par un «plancher hideux» (comprendre: plafond), déjà en partie détruit ${ }^{23}$.

En ce premier quart du XIX ${ }^{\mathrm{e}}$ siècle, les vestiges de la chapelle furent agrandis à l'ouest, au-delà de la porte $(1813)^{24}$, comme le figure le plan du cadastre dit «napoléonien » de $1829^{25}$, à l'emplacement de la nef disparue; l'ancien chœur devint laboratoire de chimie, après obturation des fenêtres du chevet et mise en service de la porte percée dans le mur nord ${ }^{26}$. Cette porte de petite taille, peut-être héritée des dispositions antérieures à la destruction de 1772, en tout cas attestée en 1836, fut agrandie jusqu'à $3 \mathrm{~m}$ de large en 1834, afin d'y faire entrer des canons donnés à la ville par Louis Philippe ${ }^{27}$. Cet agrandissement et le percement d'une fenêtre quadrangulaire ${ }^{28}$ au-dessus obligèrent à supprimer le contrefort central du mur nord ${ }^{29}$, sans affecter toutefois ses fondations.

En 1868-1869, une consolidation générale du bâtiment fut entreprise par l'aumônier et les élèves du collège ${ }^{30}$, ouvrant un conflit avec l'administration des Monuments historiques sur la question du couvrement du chœur. Le ministre des Beaux-Arts exigeait un projet de restauration dûment documenté avant de délivrer

20. CoUANON, 1986, p. 77, n. 20.

21. Caen, Arch. dép. Calvados, 386 E dépôt 499 (12 pluviôse an VI/1798).

22. Ibidem, dépôt 497 (4 messidor an XI/1803).

23. Paris, Méd. du Patrimoine, 81/14/355/1, carton 106, annotations d'une lettre de l'aumônier Berthé au prince impérial (30 mars 1868).

24. HUREL, 1896, p. 13, p. 192.

25. Caen, Arch. dép. Calvados, 3P, Falaise, section E2.

26. Ibidem.

27. Caen, Bibl. mun., FN E 850 et L 285.

28. Paris, Méd. du Patrimoine, 81/14/355/1, carton 106, le maire de Falaise au ministre des BeauxArts (2 août 1869).

29. Ibidem, l'aumônier Berthé au prince impérial (30 mars 1868). HUREL, 1896, p. 13, p. 192

30. Le coût élevé des travaux pour l'administration scolaire $(8000 \mathrm{~F})$ entraîna une recherche active de capitaux de mars à juin 1868. Le 30 mars 1868, les élèves s'adressent au prince impérial pour obtenir des crédits [Paris, Méd. du Patrimoine, 81/14/355/1, carton 106, Berthé au prince impérial (30 juin 1868)]. En juin, une souscription parmi les élèves et les habitants rapporte $2500 \mathrm{~F}$ [Paris, Méd. du Patrimoine, 81/14/355/1, carton 106, le ministre de l'Instruction publique au ministre des BeauxArts (18 juin 1868)]. Un professeur de philosophie du collège organise une loterie [Paris, Méd. du Patrimoine, 81/14/355/1, carton 106, Ruprich-Robert au ministre des Beaux-Arts (15 mai 1869)]. 
tout crédit ${ }^{31}$. Mais, pourtant signalée cinq ans auparavant par Victor Ruprich-Robert parmi les édifices insignes de l'enceinte ${ }^{32}$, la chapelle fut soumise aux travaux sans consultation du service des Monuments historiques. Les travaux consistèrent à faire sauter le plafond déjà cité et à couvrir le chœur d'une voûte de plâtre reposant sur des ogives en arc brisé. En mai 1869, Ruprich-Robert décrit l'étendue des dégâts au ministre des Beaux-Arts et sollicite l'interruption des travaux et la suppression des voûtes ${ }^{33}$. Eugène Viollet-le-Duc, lors de la séance de la commission des Monuments historiques du 30 juin suivant, autorise cette démolition ponctuelle au profit d'une restauration "décente» et "réelle», imputant les dépenses sur les crédits affectés à la restauration du donjon ${ }^{34}$. Le maire de Falaise se défend en soulignant l'indépendance géographique de l'ancienne chapelle par rapport aux éléments du château protégés par les Monuments historiques ${ }^{35}$. En mai 1870, les voûtes de plâtre étaient toujours en place ${ }^{36}$. Émile Bœswillwald, inspecteur des Monuments historiques,

31. Paris, Méd. du Patrimoine, 81/14/355/1, carton 106, le ministre des Beaux-Arts au ministre de l'Instruction publique (23 juin 1868).

32. Ibidem, lettre au ministre des Beaux-Arts, évoquant son rapport du $1^{\text {er }}$ novembre 1863 (15 mai 1869).

33. Ibidem, le ministre des Beaux-Arts au ministre de l'Instruction publique (23 juin 1868): «On incruste des colonnettes et des chapiteaux dans les murs où il n'en existait pas: on retaille les anciens parements $d u X I I^{e}$ siècle, autrefois très bien layés; on a remplacé au sud une fenêtre du XIII siècle par une autre baie: des voûtes en plâtre vont être élevées sur des murs dont elles détermineront certainement la ruine, car ces murs, très déversés depuis longtemps, n’ont jamais eu à supporter de voûtes». Le 12 juin, constatant que, malgré ses avertissements, les voûtes ont été mises en place, il demande leur suppression pour une somme de 4000 F [Paris, Méd. du Patrimoine, 81/14/355/1, carton 106, lettre au ministre des Beaux-Arts (12 juin 1869)].

34. Ibidem, rapport de Viollet-le-Duc (30 juin 1869).

35. «Cette chapelle [...] n'est pas du tout par sa situation une dépendance de ce qu'on appelle maintenant le château : elle en est éloignée de plusieurs centaines de mètres; elle en est séparée par les bâtiments du collège, dans lesquels elle est comme enclavée au moins d'un côté, et ces bâtiments, quoique bien plus rapprochés du donjon que la chapelle, n’ont jamais été considérés comme classés, par le motif qu'ils seraient une dépendance du château à cause de leur situation dans l'ancienne enceinte fortifiée ». Menacé d'un blâme administratif par le préfet du Calvados, le maire ajoute une description des travaux effectués: "L'édifice est d'architecture romane. Il y avait dans le gable nord-est [...] trois petites fenêtres agglomérées qui étaient entièrement bouchées. Notre premier soin a été de les déboucher et de les rendre à leur destination. Sur les côtés, deux fenêtres restaient du style primitif, les autres avaient été dénaturées. Il y a plus, on avait abattu, coupé en deux, un pilier butant et en travers, on avait ouvert une porte de trois mètres de large, surmontée d'une poutre en bois faisant portail et au-dessus, une grande fenêtre carrée avait été établie. Nous avons fait relever le pilier butant, supprimer la porte et la fenêtre carrée qui le coupaient en deux et nous avons rétabli dans leur style primitif, en suivant les modèles que nous avons sous les yeux, la fenêtre dénaturée ou supprimée. Enfin, à la place d'un ignoble plancher en bois vermoulu placé il y a 50 ans sur les sommiers d'une charpente moderne, puisqu'elle fut refait à la même époque, nous avons établi une charmante voûte à compartiments et à nervures exécutée sur le modèle de celle que M. Ruprich-Robert a élevé à Caen dans l'église Sainte-Trinité, dont la construction remonte à une époque très rapprochée de celle de la chapelle qui nous occupe et par conséquent du même style " [Paris, Méd. du Patrimoine, 81/14/355/1, carton 106, lettre au ministre des Beaux-Arts (2 août 1869)]. Le ministre ne pouvait, selon lui, reprocher à l'administration falaisienne d'avoir mis en place des voûtes d'ogives neuves (voûte à compartiments et à nervures), dans un édifice du XII ${ }^{\mathrm{e}}$ siècle, puisque Victor Ruprich-Robert lui-même en avait fait de même à la Trinité de Caen dans un édifice de la fin du XI ${ }^{\mathrm{e}}$ siècle.

36. Ibidem, Ruprich-Robert au ministre des Beaux-Arts (10 mai 1870). 
dépêché à Falaise par le ministre des Beaux-Arts, déplore en juin 1870 la perte définitive des caractères de l'édifice ${ }^{37}$ et juge désormais inutile toute démolition ${ }^{38}$. Qualifiant l'acte de vandalisme, le ministre des Beaux-Arts prévint le préfet du Calvados qu'il tenait l'administration locale pour « responsable des désordres et dégradations qui menacent de survenir dans la construction de la chapelle à la suite des travaux exécutés» ${ }^{39}$.

Le collège, implanté dans le château, nécessita, au début des années 1880, des travaux d'agrandissement. Un devis de l'architecte Carayon, en 1881, révèle le projet d'installer le parloir et la bibliothèque dans le chœur de l'ancienne chapelle et de réparer les couvertures pour l'occasion ${ }^{40}$. Les deux pièces devaient être séparées par une cloison percée d'une porte [fig. 8c]. Un plan de 1885 projette l'implantation de rayonnages dans le chœur médiéval, partout où les voûtes ménageaient une hauteur maximale ${ }^{41}$. Au début du XX $\mathrm{XX}^{\mathrm{e}}$ siècle, l'intérieur apparaît très remanié; la chapelle désaffectée servait, en 1902, de soute à charbon ${ }^{42}$. En 1908, sont cités des «supports composés d'une demi-colonne sur pilastre, flanqué de deux quarts de colonne » ${ }^{43}$; deux chapiteaux romans subsistaient en 1909, selon R. Gobillot ${ }^{44}$. En juin 1944, l'édifice fut détruit par l'explosion d'une bombe, et l'ensemble, nivelé au bulldozer. Seuls le dallage et quelques pierres des murs étaient encore visibles au début des fouilles menées en 1985-1986.

\section{Description et interprétation de l'édifice médiéval d'après les vestiges du chœur}

\section{Bilan du sondage archéologique de 1985-1986}

Le décapage d'un terrain rectangulaire de $16,50 \times 8 \mathrm{~m}$ et la suppression des gravats issus de la démolition du collège, à l'ouest, ont permis de dégager les structures

37. Ibidem, lettre au ministre des Beaux-Arts (4 août 1869) : " On se dépêcha [...] de faire retailler tous les parements de l'intérieur et de gratter à vif les bases et les bandeaux, de manière à obtenir des surfaces bien blanches. On compléta les colonnes dont la construction avait été abandonnée au XII siècle et l'on disposa le tout pour l'établissement d'une voûte. Mais les contreforts peu saillants de la chapelle étaient trop faibles pour résister à la pression d'une voûte en pierres, on n’hésita pas à exécuter une voûte d'arêtes, avec voussoirs et nervures moulés en pâtre, portant des profils qui témoignent de l'ignorance du restaurateur. De plus, craignant que le plâtre n'exerçât une trop grande pression sur les murs en partie déchaussés, on rattacha le plus possible de cette voûte à la charpente au moyen de tringles scellés dans des claveaux moulés et cloués après les bois du comble. À l'exception des deux chapiteaux de la pile d'entrée, dont la sculpture a, par sa finesse, rebuté les gratteurs à neuf, cette chapelle n'offre, à l'intérieur, plus aucun intérêt ».

38. "Faire démolir les voûtes en plâtre et remettre les choses en l'état ancien ne rendrait à ce monument, ni la taille du XII siècle de ces parements, ni le galbe des profils de ces fenêtres, bandeaux et bases de colonnes, etc.».

39. Paris, Méd. du Patrimoine, 81/14/355/1, carton 106, lettre du préfet du Calvados (29 juillet 1870).

40. Caen, Arch. dép. Calvados, 386 E dépôt 491 (6 décembre 1881).

41. Caen, Arch. dép. Calvados, 386 E dépôt 493.

42. CoUANON, 1986, p. 77, n. 22.

43. Congrès archéologique de France (ci-après C.A.F.), 1908, p. 387.

44. Gobillot, 1909, p. 25. 
de l'ancien chœur de 11,90 x 7,60 m, hors contreforts, dans une zone très perturbée à l'époque moderne et contemporaine et dépourvue de niveaux d'occupation, notamment à l'ouest du sondage [fig. 7] ${ }^{45}$. À chevet plat et à 2 travées, le chœur présente une superficie intérieure de $52 \mathrm{~m}^{2}$ environ (9,70 x 5,40 m). Les murs, épais d'1,10 m, sont élevés sur une fondation d'1,20 à 1,50 m de large, reposant sur la roche, sans trace d'égalisation préalable de celle-ci. Les fondations sont de pierre calcaire de petite taille, liée à l'argile sableuse. Les murs, conservés seulement pour la face nord, sont constitués d'un blocage de calcaire maintenu entre deux parements inégaux: moellons irréguliers de 0,15 m de côté environ, pour le parement interne; blocs de calcaire taillés, liés par un mortier de chaux gris très sableux pour le parement externe. Le mur nord était soutenu par trois contreforts plats: deux aux angles; un au centre. Pour le mur est, les fondations d'un autre contrefort ont été dégagées à l'angle nordest, en limite de sondage.

À l'intérieur du chœur, les fondations de deux piliers ont été observées au milieu de chacun des murs nord et sud, correspondant, pour le parement externe du mur nord, à l'implantation du contrefort médian. Dans l'angle nord-est, une zone de 3,50 x 1,50 m a livré, sous le dallage moderne, une couche de terre grise de remblai, reposant sur un niveau de sol, surmontant lui-même une couche de graviers, d'argile ocre et de tessons de céramique attribués au XVI ${ }^{\mathrm{e}}$ siècle. Autour du contrefort de l'angle nord-ouest, la tranchée de fondation du mur nord et du contrefort, creusée dans une terre argileuse grise, qui reposait sur la roche, contenait trois fragments de poterie, attribués aux XII ${ }^{\mathrm{e}}$-XIII ${ }^{\mathrm{e}}$ siècles. Deux structures antérieures à la construction du chœur sont apparues par ailleurs. L'une, orientée nord-ouest/sud-est, située à l'extérieur du chœur, au nord-ouest du sondage, était composée d'un rang de galets de schiste large de 0,40 m [repère G]. L'autre, de même orientation, coupée par la fondation du mur nord, était composée de pierres calcaires et de galets de schiste et se prolongeait sous le dallage de la chapelle, non déposé dans cette zone [repère $\mathrm{H}$ ].

\section{Plan et élévation de la chapelle castrale médiévale}

Si l'on se reporte au plan de 1744-1747 cité précédemment, on suppose que la nef représentait trois fois la surface du chœur et qu'elle devait donc occuper approximativement un terrain de $150 \mathrm{~m}^{2}$. Des témoignages contemporains de sa démolition en $1772^{46}$ corroborent l'hypothèse d'une chapelle de grande taille.

La porte principale de la chapelle, dans l'axe de la nef, était au bas Moyen Âge précédée d'un porche (prosnel), pourvu d'un seuil et d'un toit de charpente, cités par la comptabilité en $1407^{47}$. En 1613, ce porche se trouve encore mentionné dans

45. Ceci corrige les mesures jadis avancées de 11,40 x 5,40 m [HUREL, 1896, p. 13].

46. Voir La Perelle à l'intendant Jullien [Alençon, Arch. dép. Orne, C 6 (5 juin 1772) : « la chapelle [...] est effectivement très grande et en mauvais estat »] et la lettre du prieur de Saint-Jean [Alençon, Arch. dép. Orne, C 6 (17 juin 1772) [ « cette chapelle ne consiste pas seulement en un chour et chancel, mais encore en une nef assés vaste parce qu'anciennement il y avoit plusieurs ménages dans l'enceinte du château, qui formaient les paroissiens de cette chapelle»].

47. Voir annexe I, $\mathrm{n}^{\circ} 11$. 
un devis de fourniture de deux sablières et d'une poutre dite «fillière », longues de 16 pieds, pour restaurer cette charpente. La sablière est une pièce horizontale; on peut estimer que le porche mesurait donc environ 4,80 m de largeur ou de longueur ${ }^{48}$.

Le chœur à chevet plat est un parti architectural commun à plusieurs églises paroissiales ou rurales de Normandie, de la fin du XI ${ }^{\mathrm{e}}$ siècle à l'orée du XIII ${ }^{\mathrm{e}}$ siècle, situées aux alentours même de Falaise ${ }^{49}$, ou plus éloignées ${ }^{50}$. Le chœur, sans doute du XIe siècle, de la chapelle priorale de Saint-Arnoult, au Mont-Canisy, comportait également deux travées rectangulaires, séparées à l'extérieur par des contreforts plats. Au nord seulement, il était éclairé d'étroites fenêtres à fort ébrasement sous linteau monolithe. On retrouve deux travées à Saint-Léonard de Vains, dans le chœur de l'église priorale, daté du début du XII siècle. Ce type, à chevet plat et deux travées, caractérise aussi le chœur de Saint-Germain de Cintheaux, construit au milieu du XII ${ }^{\mathrm{e}}$ siècle, dont le chevet plat fut refait en 1865, et ceux de Saint-Ébremond de La Barre-de-Semilly et de la chapelle priorale de Saint-Pierre à Noron-l'Abbaye, du deuxième tiers du XII ${ }^{e}$ siècle, le chœur presque intact de Sainte-Colombe-enCotentin, du XII ${ }^{e}$ siècle, ou celui de Saint-André d'Hébertot, avec un décor d'esprit roman.

Dans ce contexte architectural, les dimensions du chœur de la chapelle de Falaise et son plan rectangulaire, à chevet plat et 2 travées, appellent une comparaison plus fine avec le plan de l'église paroissiale de Thaon, assez proche géographiquement [fig. 3]. Construite sur une courte période, de la fin du XI ${ }^{\mathrm{e}}$ au milieu du XII ${ }^{\mathrm{e}}$ siècle, l'église de Thaon, très remaniée à l'époque moderne et contemporaine, est connue en élévation par une gravure de 1769. Pour un chœur de 14 x 5,10 m, dégageant une superficie de $71 \mathrm{~m}^{2}$ environ, l'église de Thaon comportait une nef rectangulaire, jamais voûtée, mais couverte d'une charpente. Elle offrait une superficie de 137,75 m². On retrouve donc, avec des dimensions comparables, quasiment le même rapport de surface chœur/nef qu’à Falaise.

\section{Les parties hautes}

Comme à Cintheaux, la chapelle de Falaise disposait d'un clocher, cité en 1391, à l'aplomb de l'autel ${ }^{51}$, encore en élévation et couvert d'essentes en 1613, alors qu'à l'époque médiévale, la chapelle castrale était couverte de tuiles de Barbery, selon les textes de 1391 et $1407^{52}$. Le chœur était encore couvert de tuiles à la fin du XVIII et

48. Caen, Arch. dép. Calvados, C 1697 (20 août 1613).

49. Notre-Dame de Beaumais, Saint-Germain de Cintheaux, chapelle priorale de Saint-Pierre à Noronl'Abbaye, Saint-Laurent de Vaton, Saint-Gervais de Jort, Sainte-Anne de Norrey-en-Auge.

50. Église de Thaon, avec un chœur du XII ${ }^{\mathrm{e}}$ siècle, chapelle priorale de Saint-Arnoult au Mont-Canisy, Saint-Pierre de Touques, église priorale de Saint-Léonard de Vains, Saint-Manvieu de Meuvaines, Saint-Ébremond de La Barre, Saint-Étienne de Beaumesnil, Sainte-Colombe en Cotentin, à Chef-duPont, Saint-André d'Hébertot ou Saint-Loup-Hors à Bayeux [MUSSET, 1987, p. 28-31, p. 34-36, p. 40, p. 42-43].

51. Voir annexe $\mathrm{I}, \mathrm{n}^{\circ} 5$.

52. Voir annexe $\mathrm{I}, \mathrm{n}^{\circ} 5,7$ et 12 . 
au début du XIX siècle $^{53}$. En 1803, chaque pan de la toiture du chœur était large d'11,70 $\mathrm{m}$ pour $7 \mathrm{~m}$ de haut ${ }^{54}$. Au sommet du pignon est se dressait une croix, datée du XIII ${ }^{\mathrm{e}}$ siècle en $1908^{55}$, dont Ruprich-Robert a laissé un dessin en 1869 [fig. 4d].

Sous le plafond ruiné cité en 1805, le chœur de la chapelle de Falaise, en 1790, était couvert d'une charpente lambrissée traitée en voûte en berceau ${ }^{56}$. Lors de la mise en place, jugée restitutive en 1869, de voûtes en plâtre stylistiquement anachroniques, Victor Ruprich-Robert, venu analyser les maçonneries des parties inférieures, avançait l'idée d'un changement de parti en cours de construction et l'absence définitive de tout couvrement de pierre:

- « [l]es murs [...] n'ont jamais eu à supporter de voûtes et si, au début de la construction, on avait eu l'idée d'en établir, il paraissait certain [...] que la chapelle avait été achevée sans l'intention d'en faire ${ }^{57}$.

En 1870, Émile Boeswillwald interprétait de même les indices de ce projet avorté, «disposition si intéressante pour l'histoire de l'art et de la construction au XII' siècle»:

- «À l'origine, le plan de cette construction du XII siècle avait été exécuté jusqu'à hauteur d'un mètre du sol avec l'intention de voûter la chapelle. Mais, arrivé à ce point, on abandonna ce système par suite de l'insuffisance de force des contreforts et les murs furent continués jusqu'à la corniche de couronnement, appareillés et taillés avec un soin tout particulier. La voûte (comprendre: de pierres), abandonnée, fut remplacée par une charpente apparente (comprendre: traitée en berceau) ${ }^{58}$.

Dans les chœurs à chevet plat des édifices romans de Normandie méridionale, la question du couvrement fut réglée la plupart du temps par la mise en place d'une voûte : soit voûte en berceau supportée par un arc-doubleau massif, comme à SaintPierre de Touques, dont les parties basses peuvent remonter à la fin du XIe siècle, solution rare en Normandie, adoptée également à la crypte de Saint-Arnoult (Deauville); soit voûte d'ogives, comme à Saint-Manvieu de Meuvaines (chœur du XII siècle), Saint-Pierre à Noron-l'Abbaye (chœur du deuxième tiers du XII ${ }^{\mathrm{e}}$ siècle, percé ensuite d'une fenêtre rayonnante), Sainte-Colombe en Cotentin (chœur quasi intact $\mathrm{du}$ XII ${ }^{\mathrm{e}}$ siècle), Saint-André d'Hébertot (voûte d'ogives contemporaine de la construction du chœur, au XIIe siècle) et Saint-Gervais de Jort (début du XIII siècle).

Seul le chevet a fait l'objet d'une photographie vers 1890, publiée dans La Normandie monumentale et pittoresque [fig. 5]. Selon cette vue, les dessins de 1869 [fig. 4a à d] et les textes contemporains (1869-1908), il était percé d'un triplet, couvert

53. Caen, Arch. dép. Calvados, 386 E dépôt 499 (8 novembre 1790), 386 E dépôt 497 (4 messidor an XI/ 1803).

54. Ibidem, dépôt 497 (4 messidor an XI/1803).

55. C.A.F., 1908, p. 386.

56. Caen, Arch. dép. Calvados, 386 E dépôt 499 (8 novembre 1790).

57. Paris, Méd. du Patrimoine, 81/14/355/1, carton 106, lettre au ministre des Beaux-Arts (15 mai 1869).

58. Ibidem, (14 juin 1870). 
d'arcs en plein cintre ${ }^{59}$. Les murs nord et sud étaient percés chacun de deux baies, selon le plan et l'élévation nord de Carayon de 1881 [fig. 8e], parmi lesquelles Victor Ruprich-Robert, en 1869, signalait «deux fenêtres [...] du style primitif; les autres [...] dénaturées ». Le mur nord étant bien connu par l'iconographie, c'est donc dans le mur sud qu'était percée une baie reprise au XIII ${ }^{\mathrm{e}}$ siècle ${ }^{60}$, signalée par Carayon en 1869 et décrite par J.-M. Hurel en 1896 comme une baie à trois lancettes couverte d'un arc brisé ${ }^{61}$.

\section{Les décors du chour}

Le décor extérieur du chœur était composé d'une moulure continue, composée d'oves cantonnées de chevrons, signalée par la majorité des observateurs ${ }^{62}$, et relevée par Ruprich-Robert en 1869, puis Danjoy en 1891 [fig. 4 et 6]. Elle courait sur les trois faces du chœur, cernant les contreforts et soulignant l'allège des baies. Sous la saillie des versants du toit, comme dans le cas de la nef romane de la chapelle castrale de Caen, les détails du mur nord par Ruprich-Robert (1869) et Carayon (1881) montrent l'existence d'une corniche à modillons rythmant la dernière assise [fig. 2 et 4] . Le pignon du chœur en était dépourvu.

Quant au décor intérieur du chœur, J.-M. Hurel signalait en 1896 «les chapiteaux à palmettes des colonnes qui en occupent le centre» ${ }^{63}$. Ruprich-Robert donne en 1869 le croquis, repris et complété par Danjoy en 1891 [fig. 4 et 6], du chapiteau de l'un de ces piliers qui supportaient la retombée des arcs, plaqués contre le parement intérieur des murs délimitant les deux travées des murs nord et sud. Les arcs plaqués du mur du chevet étaient en plein-cintre, tandis que ceux du mur nord étaient brisés. Comme à l'extérieur, l'allège des baies était soulignée, à l'intérieur du chœur, par une moulure horizontale, interrompue par le pilier médian de chaque mur-gouttereau et par les piliers d'angle.

Comparée aux édifices religieux romans de Normandie méridionale à chevet plat déjà cités, au Mont-Canisy, à Touques, à Cintheaux, l'ornementation extérieure et intérieure du chœur de la chapelle castrale de Falaise se caractérise par une pureté de lignes, dépourvues d'ornementation superflue, confinant même par endroits à la sécheresse. L'ampleur de l'édifice de culte, que l'on peut déduire du volume du chœur, et la régularité de l'appareil de pierre calcaire des parements extérieurs du chœur, dégagé lors du sondage de 1986, sont des critères d'une architecture de haute qualité, mais en l'absence de pièce graphique ou de description antérieure à 1772, le décor de la nef elle-même demeurera parfaitement inconnu.

59. Trois «petites fenêtres agglomérées » pour le maire de Falaise (1869); «triple arcade romane du chevet oriental» pour J.-M. Hurel [HUREL, 1896, p. 12] ou le Congrès archéologique de France [C.A.F., 1908, p. 386].

60. Paris, Méd. du Patrimoine, 81/14/355/1, carton 106, lettre au ministre des Beaux-Arts (15 mai 1869).

61. HuREL, 1896, p. 12 : fenêtre ogivale à trois baies, vers le sud.

62. C.A.F., 1908, p. 386

63. HuREL, 1896, p. 12. 


\section{Datation de l'édifice}

À propos de la chapelle castrale de Falaise, Ruprich-Robert, en 1863 et 1869, évoquait une "très jolie chapelle $d u$ XII ${ }^{e}$ siècle» ${ }^{64}$. L. Braquehais, en 1895 , la datait du XII ${ }^{e}$ siècle ${ }^{65}$. Selon les sources graphiques et photographiques anciennes publiées ici, le plan du chour, le type et la disposition des ornements sculptés correspondent, en effet, à un édifice bâti avant 1200. Pour autant, des éléments mettent en évidence diverses époques de construction. Du XII siècle datent les parements layés des murs du chœur ${ }^{66}$, la triple arcade du chevet, encadrée d'un tore continu, la corniche à modillons, les chapiteaux à palmettes des piliers médians, les fonts baptismaux. Du XIII siècle date la baie sud à trois lancettes sous arc brisé. Quoique les constats archéologiques des sépultures en place en 1986 attestent la grande antériorité de l'usage funéraire du lieu ${ }^{67}$, il faut souligner l'absence de sources textuelles avant 1200, qui documenteraient les travaux de construction menés sous tutelle ducale, avant le remaniement sous tutelle capétienne après 1204. En 1200, deux chapelles au moins existaient dans le site castral de Falaise, une charte du roi Jean Sans Terre mentionnant au pluriel les "capellas in castello nostro de Falesia sitas" ${ }^{68}$. Il s'agit en toute hypothèse de celles de la tour-résidence et de la basse-cour, dont il confie la tutelle à l'abbé de Saint-Jean de Falaise.

\section{Les travaux de restauration et d'entretien du bas Moyen Âge}

\section{Aménagements et décors intérieurs}

L'autel, ou le prestre chantoit, cité en 1391, était situé à la verticale du clocher, alors qu'au XIX siècle, il était adossé au mur du chevet à l'est ${ }^{69}$. En 1414, la chapelle disposait d'un sacraire, ou armoire eucharistique, ménagé dans un mur voisin de l'autel et fermé par une petite porte, qu'un serrurier dote d'une clef en $1414^{70}$. Un

64. Paris, Méd. du Patrimoine, 81/14/355/1, carton 106, lettre au ministre des Beaux-Arts (15 mai 1869).

65. BRaqueHAIS, 1895, t. II, p. 52.

66. Paris, Méd. du Patrimoine, 81/14/355/1, carton 106, Ruprich-Robert au ministre des Beaux-Arts (15 mai 1869).

67. La chapelle castrale avoisinait trois rochers dûs à l'affleurement du socle lithique, auxquels l'abbé Langevin donnait le sens de monuments druidiques, symboles du triple globe de la terre, de la lune et $d u$ soleil, et attribuait une origine celtique [LANGEVIN, 1814, p. 17, n. 1]. Repris par A. Mériel [MÉRIEL, 1889, p. 2], Langevin considérait le château comme une enceinte druidique, cernant un autel de sacrifices [LANGEVIN, 1814, p. IX, p. XXV-XXVI et p. XXXV, p. 5 et 17, n. 1].

68. Gallia christiana, t. XI, col. 755.

69. Voir annexe $\mathrm{I}, \mathrm{n}^{\circ}$ 5. Sa décoration, très probablement moderne, est décrite en novembre 1790 , alors que la destruction de la nef a modifié son emplacement d'origine; l'autel est précédé de deux marches, orné d'une Assomption et d'une Descente de croix, peintes à l'huile [Caen, Arch. dép. Calvados, 386 E dépôt 499 (8 novembre 1790) ]. L’implantation moderne est donnée par une lettre de 1869 [Paris, Méd. du Patrimoine, 81/14/355/1, carton 106, le maire de Falaise au ministre des Beaux-Arts (2 août 1869)].

70. Voir annexe I, n 16. Ils n’apparaissent pas sur les croquis du chœur des années 1860-1880. 
retrait servait en outre, depuis 1442 au moins, à ranger les ornements et les vêtements liturgiques utiles à la célébration de l'office ${ }^{71}$. L'édifice comportait des bancs de pierre pour les fidèles: ne figurant pas sur les croquis du chœur des années 1860-1880, ils purent être implantés le long des murs de la nef. Deux de ces bancs furent restaurés en $1459^{72}$. Vers 1340-1350, les baies de la chapelle étaient pourvues de verrières, maintenues par des vergettes métalliques ${ }^{73}$. Les travaux de consolidation des vergettes alors menés furent repris en $1423^{74}$. Les verrières étaient-elles, dès 1340-1350, pourvues de verre polychrome? Lors des travaux de 1381, à tout le moins, la polychromie était présente aux verrières de la chapelle: en décembre 1381, un peintre de Falaise, Fouquet Le Peintre (Fouquet Le Paintour) délivrait une quittance pour la mise en place de verrières polychromes au milieu du mois ${ }^{75}$.

Parmi le mobilier liturgique, citons un calice d'argent, lourd d'1 marc 1 once, acheté en 1373 sur ordre des maîtres de la Chambre des comptes du roi, pour remplacer un calice dérobé aux chapelles du château de Falaise ${ }^{76}$. En 1380, le chasublier Guillaume de Baugis, bourgeois de Paris, fournit, pour la provision et garnison de la chappelle du chastel, un vêtement liturgique complet, dont le coût (11 $\mathfrak{E} 10$ s.t.) se justifie sans doute par le choix des étoffes et un travail de broderie élaboré. Guillaume, abbé de Saint-Jean, qui jouit du bénéfice des chapelles castrales, reçoit la parure avant le $1^{\text {er }}$ novembre ${ }^{77}$. En 1391, l'administration achète un bénitier de cuivre à un dinan$\operatorname{dier}^{78}$. En 1408, enfin, un serrurier de Falaise fournit un chandelier de métal à l'usage de la chapelle castrale ${ }^{79}$.

\section{Usage et entretien de l'édifice médiéval}

À compter du milieu du XIVe siècle, les sources comptables documentent les travaux menés par l'administration royale déléguée.

- L'usage des combles des chapelles castrales. En 1380, selon l'inventaire des stocks de vivres et de matériaux, des dépôts sont aménagés dans les combles et greniers des deux chapelles castrales, différenciées par les termes de chappelle et, pour désigner la chapelle située dans la cour, de chappelle du chastel. L'usage d'espaces aussi proches du lieu de culte ne doit pas surprendre dans un site soumis à une contrainte résidentielle de masse (personnel permanent, garnison à effectif variable). Au château

71. Ibidem, $\mathrm{n}^{\circ} 23$.

72. Ibidem, $\mathrm{n}^{\circ} 28$.

73. Ibidem, $\mathrm{n}^{\circ} 1$.

74. Ibidem, $\mathrm{n}^{\circ} 17$

75. Ibidem, $\mathrm{n}^{\circ} 3$.

76. Paris, BnF, ms fr. 25 973, $\mathrm{n}^{\circ} 2155$ ( $1^{\mathrm{er}}$ novembre 1373) : «Cum dudum latrones furtives spoliassent cappellas domini nostri regis in suo castro Falesie a quodam calice».

77. Composée d'une chasuble, d'une étole, d'un fanon, d'une aube et d'un amit. Voir Paris, BnF, ms fr. $20906, \mathrm{n}^{\circ} 52$ (15 octobre 1380 ) et $\mathrm{ms}$ fr. $20906, \mathrm{n}^{\circ} 51$ ( $1^{\text {er }}$ novembre 1380$)$.

78. Voir annexe $\mathrm{I}, \mathrm{n}^{\circ} 5$.

79. Voir annexe $\mathrm{I}, \mathrm{n}^{\circ} 15$ 
d'Argentan (Orne), la chapelle du shell-keep, en 1437, offrait le même usage ${ }^{80}$. La perception des volumes de la chapelle de la cour est malaisée du fait de la disparition de la nef en 1772; mais cette dernière était susceptible d'offrir un volume de combles important, monopolisé par l'administration comme dépôt de vivres. En 1430 encore, le grenier au-dessus de l'une des deux chapelles est utilisé comme dépôt de grains, dont la gestion relevait du capitaine: le texte mentionnant des travaux de couverture, il s'agit vraisemblablement du grenier de la chapelle de la cour ${ }^{81}$.

- Les travaux de couverture. Les intempéries de la nuit de Noël 1390 entrainèrent la chute du clocher. Les tuiles d'une vielle cuisine du tinel du chastel servirent à restaurer la couverture dégradée (emplacement du clocher, à l'aplomb de l'autel, et pignon de la chapelle) durant le premier trimestre 1391; selon une pratique bien attestée, les tuiles furent maintenues au mortier de chaux et de sable ${ }^{82}$. Une cloche neuve, lourde de 55 livres, remplaçant celle déplacée dans le château pour la sonnerie du guet, fut mise en place en 1405 par un fondeur de cloches (saintier) de Sées ${ }^{83}$. Le porche, récemment édifié, fut couvert de lattes et d'essentes, entre mars et septembre $1407^{84}$, puis sans doute de tuiles de Barbery, dont la livraison pour la chapelle intervient entre la fin juin et octobre, calant les travaux entre juillet et septembre 1407, aux beaux mois de l'année ${ }^{85}$. Une nouvelle restauration de la couverture de tuiles protégeant le grenier au-dessus de la chapelle eut lieu en $1430^{86}$.

- Les travaux de maçonnerie. À la fin de l'année 1398, un maçon fut chargé d'une réfection générale du chemin pavé qui reliait la chapelle et le logis du vicomte en pavés neufs de la carrière d'Aubigny, à moins de trois $\mathrm{km}$ de Falaise ${ }^{87}$. Avant janvier 1399, il restaura également les parements de la chapelle, partout où nécessaire, de bonne pierre assise a mortier de chaux et renforça de pierre de taille trois des piliers, terme pouvant désigner soit les contreforts extérieurs soit les supports intérieurs ${ }^{88}$. Entre mars et septembre 1407 furent encore commandés la consolidation ou le ré-

80. Alençon, Arch. dép. Orne, A 414, état des vivres du château d'Argentan (12 juin 1437) : "Item touchant vingt quatre costés de lart, pour ce qu'ilz avoient esté mis en la chappelle dud. dangon par deffaut d'aultre lieu possible a les mettre et que icelluy lieu estoit fort moite».

81. Voir annexe $\mathrm{I}, \mathrm{n}^{\circ} 19$.

82. Voir annexe $\mathrm{I}, \mathrm{n}^{\circ} 5$ et 7 .

83. Voir annexe $\mathrm{I}, \mathrm{n}^{\circ} 10$

84. Voir annexe $\mathrm{I}, \mathrm{n}^{\circ} 14$.

85. Voir annexe $\mathrm{I}, \mathrm{n}^{\circ} 12$.

86. Voir annexe $\mathrm{I}, \mathrm{n}^{\circ} 19$.

87. À la fin du XIV ${ }^{\mathrm{e}}$ siècle, en effet, la chapelle était reliée au logis vicomtal, situé le long de la courtine et achevé par la tour dite de l'Échiquier (jadis tourelle au bout de la salle au vicomte) [CHAVE, 1999, t. II], par un chemin pavé de 43 x 8,5 pieds (env. 12,90 x 2,55 m) [voir annexe I, n ${ }^{\circ} 8$ ]. Les pavés, remplacés pour certains en 1398-1399, provenaient de la carrière d'Aubigny et mesuraient chacun 2 x 15 pieds (env. 0,60 x 0,45) [voir annexe I, $\mathrm{n}^{\circ} 8$ et 9]. Formant donc une longue bande de quelque cent vingt pavés, l'ensemble était qualifié d' " allée». Désignant à la fin du Moyen Âge, le couloir, la galerie, voire le chemin de ronde, ce terme d' "allée» ne peut-il être rapproché de ces galeries de devers la chappelle, mentionnées encore en 1445, pour des travaux de maçonnerie en partie basse? [voir annexe I, $\left.n^{\circ} 24\right]$.

88. Voir annexe $\mathrm{I}, \mathrm{n}^{\circ} 9$. 
galement des dalles du porche et l'aménagement d'un enfeu pour le tombeau d'un chapelain ${ }^{89}$.

Selon J.-M. Hurel, la chapelle de la cour aurait été ruinée par le siège de 1418 et restaurée par les soins d'Henri IV qui confirma la tutelle de l'abbaye Saint-Jean, si l'abbé acceptait d'y servir le culte ${ }^{90}$. Aucune source comptable recensée n'atteste toutefois de travaux contemporains du début de l'occupation anglaise, alors que la première moitié du XVe siècle se caractérise par une diminution très nette des mentions de travaux menés à l'édifice: fourniture de vergettes en 1423, restauration de la couverture du grenier en 1430, renforcement du porche en 1434, puis renforcement de l'un des piliers - sans doute un contrefort - en 1455 seulement ${ }^{91}$. À la raréfaction des sources évoquant des travaux s'ajoute, après la libération, une fréquentation de la chapelle pour un usage extra-religieux: le conseil des bourgeois de Falaise et officiers du château la convertit à l'occasion en salle de réunion en 1448-1449 $9^{92}$.

\section{Dédicace et service du culte aux chapelles castrales de Falaise}

\section{Évolution de la dédicace}

Pour l'abbé Langevin (1814), la chapelle de la cour était placée sous l'invocation de saint Prix ou Prisc (Praejectus), tandis que la chapelle privée de la tour-résidence romane portait une dédicace à saint Nicolas ${ }^{93}$. Selon L. Musset (1967), il s'agit de l'inverse ${ }^{94}$. Selon A. de Caumont, la chapelle de la cour était placée sous l'invocation de saint Nicolas ${ }^{95}$. J.-M. Hurel (1896), relevant ce problème de dédicace, propose de penser que la chapelle fut placée sous le vocable de saint Nicolas lors de l'avènement du roi Henry IV, saint Nicolas étant le patron du jour de sa naissance (6 décembre 1422 ${ }^{96}$. Les sources documentaires conservées ne précisent pas l'invocation de la chapelle castrale avant la fin du XVe siècle. La première mention textuelle, en 1468, évoque la chapelle castrale Saint-Sulpice: les revenus et oblations de la chappelle de Saint Suppliz fondee ou chastel dud. Faloise ${ }^{97}$. En 1703 encore, l'invocation est confirmée par un acte de Louis XIV : la chappelle de Sainct-Sulpice fondee et situee dans le

89. Voir annexe I, n 11 .

90. HUREL, 1896, p. 13.

91. Voir annexe $\mathrm{I}, \mathrm{n}^{\circ} 17,19,21$ et 27.

92. Caen, Arch. dép. Calvados, 386 E dépôt 33, Compte de la recepte et despence de la ville de Faloise, par Robert Jean, receveur des bourgeois de Falaise $\left(1448,1^{\text {er }}\right.$ octobre $-1449,1^{\text {er }}$ octobre; rendu le 8 mars 1450 (n. st.)) : "Item pour iij poz de vin portez en la chapelle du chastel ou les bourgoys estoient assemblez avecquez les officiers de mon dit seigneur le conte pour le faite du guet et portes [de l'enceinte urbaine, - s'agissant de comptabilité municipale], 5 s. $8 \mathrm{~d}$.».

93. LANGEVIN, 1814, p. 7, n. 1 .

94. Musset, 1987, t. I, p. 34.

95. CAUMONT, t. II, p. 470.

96. Hurel, 1896, p. 12. CoUANON, 1986, p. 75.

97. Caen, Arch. dép. Calvados, H 4166 (1468, 19 novembre). 
chasteau est une chapelle royalle ${ }^{98}$. Mais, à compter du dernier tiers du XVIII ${ }^{e}$ siècle, en effet, un édit de Louis XVI (août 1772) et un acte des religieux de l'abbaye SaintJean de Falaise (avril 1780) évoquent la chapelle castrale Saint-Nicolas, dédicace reprise par Caumont et par les auteurs modernes ${ }^{99}$.

\section{Tutelle abbatiale, rang paroissial et célébration des sacrements}

Les religieux de l'abbaye Saint-Jean de Falaise ont reçu la tutelle des chapelles du château de Falaise du duc-roi Jean Sans Terre le 7 juin 1200, par un acte daté d'Argentan ${ }^{100}$. Le service divin devait être célébré au château par deux chanoines de l'abbaye, lors de la messe quotidienne et à toutes les heures du jour. Le duc délivrait 2 sous angevins par jour aux chanoines, qu'ils recevaient chaque année lors de la tenue de l'échiquier de Caen, au terme de Pâques, en mars ou avril, et de la Saint-Michel, le 29 septembre. Le texte de la charte royale soulève deux questions. De qui relevait le service divin avant la cession des chapelles à l'abbaye Saint-Jean de Falaise? Sans doute, un ou plusieurs chapelains attachés à la cour royale, et donc itinérants, suivaient le roi et célébraient la messe lors de ses séjours à Falaise. Que recouvre exactement l'expression "cum omnibus pertinentibus earum [cappellarum]", désignant les appartenances des chapelles castrales? Le patrimoine de l'abbaye-même est désormais mieux connu grâce aux travaux d'Isabelle Bled ${ }^{101}$; mais on ignore en quoi consistaient avant 1200 les biens relevant des chapelles du château de Falaise (rentes, terres, droits, objets liturgiques, reliques...).

Dès la conquête du duché normand, le roi Philippe Auguste confirmait la charte du roi anglais, convertissant la redevance due aux chanoines dans la monnaie imposée sur le territoire. Durant l'année 1205 - soit entre le 10 avril 1205 et le $1^{\text {er }}$ avril 1206 -, le roi accordait à Saint-Jean de Falaise $37 £ 10$ s. t. de rente, à charge d'employer deux chanoines prêtres au service quotidien des chapelles royales du château ${ }^{102}$. Selon Langevin, Henry V, à son tour, après l'occupation du château en 1418, fondait et dotait les religieux de l'ordre de Saint-Jean pour dire la messe dans la chapelle castrale les vendredis, dimanches et fêtes ${ }^{103}$. Selon un acte des années 1430, il appar-

98. Ibidem, (1703, 19 septembre. - Rouen).

99. Ibidem, (1772, 8 août. - Compiègne) : «il y a dans led. château une chapelle sous l'invocation de Saint-Nicolas qui sert de paroisse aux habitants du château ». Voir sous la même cote, l'acte du 28 avril 1780 sur la chapelle et paroisse Saint-Nicolas du chateau de Faloise.

100. Gallia christiana, t. XI, p. 755. HARDY, Rotuli Normanniae..., t. I, p. 15. HARDY, Rotuli chartarum..., t. I, part. 1, p. 69. LANGEVIN, 1814, p. 452. HUREL, 1896, p. 12. GERMAN, p. 11.

101. BLED, 1977.

102. Delisle, Actes de Philippe Auguste..., n 925, d'après une copie moderne communiquée par Lechaudé d'Anisy en 1850.

103. D’après un manuscrit appartenant à Brée l'aîné, imprimeur de Falaise [LANGEVIN, 1814, p. 363]. Il n'en est pas trace toutefois dans l'ouvrage de Léon PUISEUX, « Rôles normands et français et autres pièces tirées des archives de Londres par Bréquigny en 1764, 1765 et 1766 », Mémoires de la Société des antiquaires de Normandie, $3^{\text {e }}$ série, t. 23, 1858 ; ni dans celui de Thomas Duffus HARDY, Rotuli Normannice in turri Londinensi asservati, Johanne et Henrico quinto Anglaiae regibus, de anno 1180 nec non de anno 1417, Londres, 1835-1844, 2 vol. 
tenait aux chanoines de Saint-Jean de célébrer le culte chaque jour dans les chapelles du château, d'administrer les sacrements aux résidents du château ${ }^{104}$ et de quérir le luminaire des chapelles (cire, huile, décorations lumineuses) ${ }^{105}$. Les actes du $\mathrm{XV}^{\mathrm{e}}$ siècle évoquent le plus souvent le service divin de $\underline{l a}$ chapelle et non plus des chapelles du château ; comme si, avec l'existence de logis dans la basse-cour, celle de la tour-résidence était en voie de désaffection. Par ailleurs, les charges du début du XIII ${ }^{e}$ siècle ne sont plus strictement respectées à la fin de l'époque moderne : le service n'est plus assuré de façon quotidienne ${ }^{106}$. L'identité des célébrants est donnée par une quittance de 1373, signalant que l'abbé en personne, sinon ses vicaires, pouvait venir à l'occasion célébrer le service divin au château de Falaise ${ }^{107}$. Il semble toutefois qu'un seul chanoine se chargeait du service du culte dans la chapelle castrale: en 1407 , la chapelle castrale contient un tombeau qui abrite le «chappellain du chastel» 108 , tandis que, presque quatre siècles plus tard, en 1780, un certificat des religieux de l'abbaye est signé par un certain F. Éloge, dit curé $d u$ château ${ }^{109}$.

Durant le Moyen Âge et l'époque moderne, la stabilité des rentes dues à l'abbaye Saint-Jean en reconnaissance de ce service est un point remarquable, documenté par de nombreuses quittances, conservées aujourd'hui de façon dispersée [annexe II]. Le passage du latin au français dans leur rédaction intervient au cours des années 1420-1440. Elles sont pour la majorité délivrées par l'abbé de Saint-Jean au vicomte de Falaise, sauf celle du 7 février 1369 (n. st.), pour le versement de la Saint-Michel 1368, délivrée par le "chapelain du roi en ses chapelles du château de Falaise ", frère Jean de Maigneys, chanoine de l'abbaye Saint-Jean ${ }^{110}$. Fondé sur les recettes que l'administration tirait de la transmission ou de la vente d'un fief ou d'une propriété immobilière par un particulier dans le ressort vicomtal, comme le montre la vente du fief du Breuil, dans la paroisse de Bellou-en-Houlme, en 1514, et celle d'une maison, avec cour et jardin, située à Falaise dans la paroisse Saint-Gervais, en $1529^{111}$, le don royal comportait également des revenus des fiefs et aumônes de la vicomté de Falaise. Les sommes délivrées à l'abbé de Saint-Jean englobaient deux postes : la rémunération des célébrants et le luminaire des chapelles. La situation ne semble pas remise en cause avant le début du XV $\mathrm{XV}^{\mathrm{e}}$ siècle. Le 30 septembre 1437, Nicolas Le Pelletier, lieutenant général du vicomte de Falaise et commissaire des officiers de la chambre des comptes de Rouen, atteste la légitimité des rentes versées à l’abbaye de Saint-Jean

104. Comme au capitaine, en 1548-1575, ou au lieutenant du château, en 1624-1660 [Paris, BnF, ms lat. 10 068, col. 164-167].

105. Caen, Arch. dép. Calvados, H 4166.

106. Alençon, Arch. dép. Orne, C 6, La Pérelle à l'intendant de la généralité d'Alençon (10 juin 1772): «les prémontrés, sous la direction du prieur de l'abbaye, y font fonction curialle dimanche et feste et lorsque le cas le requiert».

107. Paris, BnF, ms fr. 25 973, $\mathrm{n}^{\circ} 2155$ (1 ${ }^{\text {er }}$ novembre 1373): «in quo divinum officium cotidie per nos [Petrum [...] humilem abbatem monasterii beati Johannis de Falesia], aut per vocarios nostros, celebratur». 108. Voir annexe $\mathrm{I}, \mathrm{n}^{\circ} 11$.

109. Caen, Arch. dép. Calvados, H 4166 (28 avril 1780).

110. Londres, B. L., Add. Ch. 10700.

111. Caen, Arch. dép. Calvados, H 4166 (26 mai 1514, 20 octobre 1529). 
deux fois l'an pour les chapelles du château. Mais les preuves documentaires, alors recherchées, semblent avoir disparu dans le dernier incendie de l'abbaye ${ }^{112}$ et contraignent l'abbé à adresser une requête au trésorier et gouverneur général des finances du roi en France et Normandie ${ }^{113}$. À la fin du XVe siècle, la légitimité des religieux de l'abbaye fut contestée aux assises de la ville par le curé de l'église de la Trinité de Falaise, paroissiale la plus proche du château, intra muros $^{114}$, et de nouveau confirmée par une sentence de l'official de Sées le 3 mars 1467 (n. st.) ${ }^{115}$. Nouvelle remise en cause en 1703, lorsque quatre résidents du château omirent de recevoir la communion pascale. Le curé de La Trinité, prétendant que la chapelle de la basse-cour relevait de la juridiction épiscopale et de la sienne propre, les assigna devant l'official de Sées; mais un acte du roi Louis XIV, en septembre 1703, confirma à l'abbé de Saint-Jean ses prérogatives sur la chapelle castrale ${ }^{116}$.

Le rang paroissial de la chapelle castrale est expressément revendiqué en 1437 par les religieux de l'abbaye, rappelant qu' ils «administrent aux gens $d u$ roy notre sire demourants aud. chateau les sacrements accoutumés a cure» ${ }^{117}$. En 1703, Louis XIV écrivait que les « roys d'Angleterre et ducs de Normandye et tous leurs domestiques [y] faisoient leurs devotions et recevoient tous les sacremens de l'église par le ministere de leurs chapelains» ${ }^{118}$. Selon Louis XVI, en 1772, la chapelle "sert de paroisse aux habitants du château» et les prieurs de l'abbaye Saint-Jean en sont "curés primitifs»" ${ }^{119}$. Cette même année, le prieur de l'abbaye rapportait à l'intendant de la généralité d'Alençon "qu'à [sa] maison seule sont réservées les fonctions curialles de cette chapelle, pour laquelle [ils tiennent] régulièrement des registres de baptême, mariages et sépultures» ${ }^{120}$. Selon M. de La Pérelle, «la chapelle du château n'a point changé depuis son ancienne création; on y baptise, marie et enterre; elle est toujours demeurée église paroissiale; [...] il est vray que son district n'est pas d'une grand [sic] estendue et ne comprend qu'un bien petit nombre d'habitants puisqu'il se borne à la seule enceinte du chasteau, [...] de sorte que c'est une église paroissiale pour un seul ménage» ${ }^{121}$. En 1780, un acte des religieux de Saint-Jean évoque encore «la chapelle et paroisse SaintNicolas du château» 122 .

112. Caen, Arch. dép. Calvados, H 4166, mandement du vicomte de Falaise (30 septembre 1437): «de laquelle ordonnance ils n'ont pas chartres, mais se lettres en furent faittes, si les ont ils perdues par les guerres que leur moustier, maisons et edifices furent pieca ars, mais s'en rapportent aux [...] comptes rendus par les receveurs d'iceluy lieu de Faloize».

113. Caen, Arch. dép. Calvados, H 4166. Voir Paris, BnF, ms lat. 10 068, fol. 115-192 : copie collationnée (4 décembre 1741).

114. Caen, Arch. dép. Calvados, H 4166 (original et copie XVII ${ }^{\mathrm{e}}$-XVIII ${ }^{\mathrm{e}} \mathrm{s}$.).

115. Paris, Bibl. nat. France, ms lat. 10 068, fol. 164-167, n 30 (analyse de 1703).

116. Caen, Arch. dép. Calvados, H 4166 (19 septembre 1703).

117. Caen, Arch. dép. Calvados, H 4166. Paris, Bibl. Nat. France, ms lat. 10 068, fol. 115-192.

118. Caen, Arch. dép. Calvados, H 4166 (19 septembre 1703).

119. Ibidem, (8 août 1772).

120. Alençon, Arch. dép. Orne, C 6 (17 juin 1772).

121. Alençon, Arch. dép. Orne, C 6 (10 juin 1772).

122. Caen, Arch. dép. Calvados, H 4166 (28 avril 1780). 
La présence des fonts baptismaux dans la nef est mentionnée en juin $1772^{123}$. Avec sa démolition, ils furent transférés dans le chœur, où J.-M. Hurel, en 1896, les décrit comme une piscine subtrilobée de style roman. Selon A. de Caumont également, la chapelle servit de lieu de célébration des mariages pour les habitants de l'enceinte ${ }^{124}$. Quant à son usage comme lieu de sépulture, P. Couanon écrivait en 1986 qu'aucun texte médiéval ou moderne ne venait l'éclairer ${ }^{125}$. D'ailleurs, il eût été normal, la chapelle étant placée sous la tutelle de l'abbaye Saint-Jean de Falaise, que les résidents décédés au château fussent transférés et ensevelis dans le cimetière de l'église abbatiale : un registre d'inhumation de l'abbaye Saint-Jean témoigne ainsi que le 17 octobre 1789, le corps d'un domestique de la marquise d'Aubigny, «décédé hier dans l'enceinte du château de la ville de Falaise», fut inhumé dans le cimetière de l'abbaye ${ }^{126}$. Or, une quittance, à l'orée du XVe siècle, atteste que la chapelle castrale put abriter une ou plusieurs chapelles funéraires, autour d'un tombeau, disposé dans un enfeu. La chapelle ainsi citée en 1407 était aménagée en l'honneur d'un chapelain ${ }^{127}$. En outre, en 1772 , lors de la démolition de la nef de la chapelle, le prieur de l'abbaye recommandait «que la partie où étoit la nef à supprimer soit regardée comme un cimetière pour lequel on doit avoir du respect et qu'on ne la mette à aucun autre usage que de [son] consentement ${ }^{128}$. Cette information de premier intérêt éclaire les constats archéologiques dressés en 1985-1986, lors du sondage implanté à l'ouest du chœur, précisément sous l'ancienne nef ${ }^{129}$. La mise au jour de cinq squelettes et

123. Alençon, Arch. dép. Orne, C 6, lettre de M. de La Pérelle à l'intendant de la généralité d'Alençon (10 juin 1772)

124. CAUMONT, t. II, p. 470.

125. COUANON, 1986, p. 75-92.

126. Caen, Arch. dép. Calvados, H 4121.

127. Voir annexe $\mathrm{I}, \mathrm{n}^{\circ} 11$.

128. Alençon, Arch. dép. Orne, C 6 (17 juin 1772).

129. Dans la partie nord de ce sondage, seule fouillée jusqu'à la roche en place, sont apparues stratigraphiquement la couche de démolition du chœur en 1945, un petit niveau de remblai apporté avant la pose du dallage qui couvrait le bâtiment du collège, évoqué plus haut, construit a posteriori en cet emplacement, puis une couche de démolition (fragments de briques, d'enduit et de tuiles), très aplanie, provenant de la destruction de l'appendice représenté par les sources graphiques du $\mathrm{XIX}^{\mathrm{e}}$ siècle, à l'emplacement de l'extrémité est de la nef. Puis, sous une couche ocre, archéologiquement vierge, de 0,10 à $0,20 \mathrm{~m}$ d'épaisseur, une couche de terre brune, mêlée de nodules calcaires, livra sur une surface de $2 \mathrm{~m}^{2}$ cinq squelettes humains orientés est-ouest, déposés en pleine terre, sans aménagements particuliers. Quatre d'entre eux reposaient presque sur la roche en place, simplement isolés par une fine couche de décomposition du schiste. Le cinquième, plus au sud, était déposé sur une couche d'argile ocre à rouge, mêlée de brins de paille, brûlés ou non, qui comblait une fosse profonde de $0,50 \mathrm{~m}$ environ, plus ou moins circulaire. Cette fosse, surmontant la couche de décomposition du schiste en place, livra un matériel de nature diverse [COUANON, 1986, p. 90 : «sept tessons de céramique commune, entièrement carbonisés; trois tessons de verrerie fine; cinq morceaux d'enduit peint jaune et rouge; une dizaine de nodules de bronze; quatorze fragments, noircis et brûlés, de marqueterie d'os et de corne, décorés de cercles pointés pour la plupart; un petit fermoir en bronze; une chaîne en bronze composée de dix mailllons rectangulaires, très finement ciselés, reliés entre eux par l'emboitement de deux tenons, fixés par une pointe de fer ou de bronze; un grand nombre de galets éclatés sous l'effet $d u$ feu; plusieurs centaines de grains d'orge et de blé carbonisés»], attribué par P. Couanon à l'époque gallo-romaine [COUANON, 1986, p. 91 : soit que 
d'une fosse associée, sous l'angle nord-est de la nef primitive, accorde crédit au témoignage du prieur de Saint-Jean et affirme la vocation de lieu de sépulture de la chapelle castrale de Falaise, au moins jusqu'à la disparition de sa nef en 1772 .

\section{Conclusion}

Mettant l'accent sur l'apport des sources documentaires à la recherche, cet article a eu pour objectif de clarifier l'analyse et l'interprétation des constats archéologiques dressés lors des fouilles de la chapelle castrale de Falaise, en 1985-1986, en montrant que seul le chœur, et non l'édifice de culte dans son ensemble, avait été alors mis au jour. Il a cherché à livrer, à travers l'iconographie de l'époque moderne, de nouvelles sources formelles aux historiens de l'architecture religieuse romane en Normandie méridionale. Autour de l'exemple de cette chapelle castrale, ces dessins, et la correspondance à l'appui, contribuent à définir sans doute aussi la mission scientifique et technique de l'administration des Monuments historiques dans la seconde moitié du XIX ${ }^{\mathrm{e}}$ siècle.

\section{Bibliographie}

BLED, Isabelle, Le patrimoine de l'abbaye Saint-Jean de Falaise, mémoire de maîtrise d'histoire, Caen, UFR d'Histoire, 1977, 105 p. (dactyl.)

BRAQUeHAIS, Léon, «Falaise», in La Normandie monumentale et pittoresque, Havre, Lemâle, 1895, t. II, p. 49-54.

Caumont, Arcisse (de), Statistique monumentale du Calvados, Paris, Derache, 1846-1857.

CHAve, Isabelle, Le château de Falaise (Calvados): étude préalable, Caen, C.R.M.H., 1999, 3 vol. (dactyl.)

Chave, Isabelle, Château de Falaise (Calvados). L'enceinte castrale et ses abords $\left(X I^{e}-X X^{e}\right.$ s. $)$ : étude archéologique et documentaire, Caen, C.R.M.H., 2002, 90 p. (dactyl.)

Congrès archéologique de France de 1908 (Caen), Paris, Picard, 2 vol., 743LXXVIII p.

Counonon, Pascal, Le château de Falaise (Calvados) : fouilles de sauvetage, Caen, S.R.A., 1986 (dactyl.)

DeLISLE, Léopold, Catalogue des actes de Philippe Auguste, Paris, Durand, 1856 (réimpr. 1975), CXXVII-649 p.

le niveau gallo-romain soit réellement en place, de façon surprenante - il n'est apparu en stratigraphie sur aucun autre lieu du site -; soit plutôt que cette sépulture ait été rapportée à une date antérieure à la construction de l'appendice occidental, accolé au chœur en 1813. Le terme indiqué dans la deuxième hypothèse par Pascal Couanon, qui ignorait l'existence de la nef détruite en 1772, doit être repoussé avant la construction de cette dernière, décrite supra]. 
Gallia christiana, t. XI., De Provincia Rotomagensi, Paris, Imprimerie Royale, 1759.

German, Paul, Histoire de Falaise, Condé-sur-Noireau, Corlet, 1945 (rééd. 1994), 485 p.

Gobillot, René, «Excursion archéologique: Falaise et la vallée de l'Orne », Bulletin de la Société historique et archéologique de l'Orne, t. XXVIII, 1909, n 1, p. 13-127.

HurEL, Jean-Marie, Le château de Falaise: étude historique, Falaise, Impr. Régnault-Trolonge, 1896, $199 \mathrm{p}$.

LANGEVIn, Paul, Recherches historiques sur Falaise, Falaise, Brée l'aîné, 1814, LXXVI-496 p.

MÉRIEL, Amédée, Histoire de Falaise: antiquité, gouvernement militaire, fortifications, Falaise, Impr. de Montauzé, 1889, 171 p.

MussET, Lucien, Normandie romane, t. I: La Basse-Normandie, Saint-LégerVauban, Zodiaque, 1967, $3^{e}$ éd., 1987, 317 p.

\section{Annexe I - Édition des sources comptables médiévales}

Remarques préalables à l'édition. L'étude ne portant pas sur les caractères externes des pièces de comptabilité, l'édition a privilégié la lisibilité et la hiérarchie des différents éléments d'un acte, à la présentation originelle très souvent compacte. De même, s'agissant d'une époque où la comptabilité est courante, les mentions chiffrées ont été converties systématiquement en chiffres arabes. Les mots omis par le rédacteur, ainsi que les mots ou passages lacunaires en raison du mauvais état du support, sont restitués dans la mesure du possible et ajoutés entre crochets carrés, à l'emplacement de leur lacune. En cas de répétition, le deuxième terme est signalé en note, à la fin de la pièce, ainsi que toutes les remarques à caractère formel. Les monosyllabes en [-es] sont accentués uniquement s'ils sont sémantiquement chargés, non lorsqu'il s'agit d'adverbes, de prépositions, de conjonctions (pres, anpres, empres, tres, apres, des, mes, etc.).

\section{1. [... 1340-1350...], terme de Pâques.}

Extrait d'un rôle de travaux au château de Falaise.

A. Orig., parch., larg. 220 x haut. $290 \mathrm{~mm}$, feuillet mutilé dans sa partie inférieure. BnF, ms fr. 25 997, n 306.

a. DeLISLE, Léopold, Actes normands de la Chambre de comptes, Rouen, A. Le Brument, 1871, p. 246-249. b. CHAVE, Isabelle, Le château de Falaise (Calvados), étude préalable, Caen, C.R.M.H., 1999, dactyl., vol. III, $\mathrm{n}^{\circ} 19$.

$[\ldots]$ 
Pour 8 verges de fer mises es fenestres de la chappelle dud. chastel achatees de Robert Voisin, 3 s.

[...]

Pour 3 cleiz mises, c'est assavoir 2 [en 1] a salle au bailli et 1 en la porte de souz la [cha] ppell [e] achatees de Pierre Le Clavier, $3 \mathrm{~s}$.

$[\ldots]$

Pour un touroil mis en l'uis de la chambre au viconte devers le compteour et appareillier celui de la porte dessouz la chapelle, $2 \mathrm{s.} 2 \mathrm{~d}$.

\section{1380, 21 juillet.}

Extrait d'un inventaire des stocks de vivres et de matériels du château de Falaise, dressé par Girot de Monfort, clerc, tabellion juré du roi de la vicomté de Falaise, et transmis par Raven Le Moine, vicomte de Falaise, à Regnault Bigaut, son successeur.

A. Orig., parch., larg. $210 \mathrm{x}$ haut. $400 \mathrm{~mm}$ et larg. $205 \mathrm{x}$ haut. $530 \mathrm{~mm}$ [des trois feuillets, les deux derniers, isolés du premier, sont cousus bout à bout; un feuillet au moins manque entre le premier et le deuxième conservés]. BnF, ms fr. 26 016, n 2711.

a. Chave, Isabelle, Le château de Falaise (Calvados), étude préalable, Caen, C.R.M.H., 1999, dactyl., vol. III, nº 77.

$[\ldots]$

Item es guerniers dessus la chappelle, 23 lanternes ferrees. Item 1003 livres de fer en pesees. Item l'esseul d'un engin rompu en deux pieces pesant 109 livres de fer. Item 24 picois acereiz pesans 78 livres de fer. Item 376 livres et demie de chanvre. Item une barre de fer pesant 38 livres de fer. Item 29 milliers de clou a late du pois de 3 livres et demie le millier. Item 5 milliers de grant clou a cheville du pois de 14 livres le millier. Item 6 milliers de clou a chantier du pois de 7 livres le millier. Item 3 seaulx neufs ferrez avec les chaines pour les puis du chastel et dongon. Item une petite neille de fer vielle au moulin a bras. Item 3 vertevelles pour pendre huis. Item 3 vieilles serreures de fer. Item une piece de corde de teil vielle de 9 toises de lont ou environ. Item 64 boisseaux de pois, mesure de Faloise, estans en l'un des garniers du dongon.

Item 29 boisseaux de fevez a lad. mesure ou garnier de dessus la chappelle du chastel.

$[\ldots]$

Et ou grenier de dessus la chappelle dud. chastel, 508 boisseaux de fourment, qui par les dessus diz boullengiers et mouniers fut rapporté en la presence dud. tabellion que il ne valloit rien et estoit de nulle valeur, parce que il avoit esté trop longuement gardé et furent lesd. pois prisiez chascun boissel $5 \mathrm{~d}$., et boissel de fevez, $6 \mathrm{~d}$. t. 


\section{1381, 29 novembre. Caen.}

Quittance du peintre caennais Pierre de Lubec à Regnaut Bigaut, vicomte de Falaise, pour 100 s. t. de travaux de peinture dans la chapelle du château de Falaise.

A. Orig., parch., larg. $270 \mathrm{x}$ haut. $70 \mathrm{~mm}$, trou d'attache dans la marge gauche. BnF, ms fr. $26018, \mathrm{n}^{\circ} 290$.

a. CHAve, Isabelle, Le château de Falaise (Calvados), étude préalable, Caen, C.R.M.H., 1999, dactyl., vol. III, n 80.

Le $19^{\mathrm{e}}$ jour de novembre l'an 1381 fut present Pierres de Lubec, paintre demourant a Caen, qui congnut avoir eu et receu de homme sage et pourveu Regnaut Bigaut, viconte de Faloise, la somme de cent souls tournois pour sa paine et salaire d'avoir fait certains euvreiges de son mestier en la chappelle du chastel de Falese qui neccessaires estoient a faire en lad. chappelle. De laquelle somme de $100 \mathrm{~s}$. t. led. painttre se tint pour bien, etc., et en quitta le roy notre sire, led. viconte et tous autres, etc.

(Signé avec paraphe:) BERENGIER AND.

Passé a Caen devant le tabellion de lad. ville.

\section{1381, 22 décembre.}

Quittance du peintre falaisien Fouquet Le Paintour à Regnaut Bigaut pour 110 s. t. de travaux de peinture dans la salle du logis manorial, la chambre du bailli et la chapelle du château de Falaise.

A. Orig., parch., larg. $280 \mathrm{x}$ haut. $100 \mathrm{~mm}$, jadis scellé sur simple queue. BnF, ms fr. $26018, n^{\circ} 298$.

a. CHAVE, Isabelle, Le château de Falaise (Calvados), étude préalable, Caen, C.R.M.H., 1999, dactyl., vol. III, nº 82.

A touz ceulz qui ces lettres verront ou orront Pierres Le Hursin, garde du scel des obligations de la viconté de Faloise, salut. Sachent que par devant Girot de Monfort, clerc, tabellion juré ou siege de Faloise, fut present Fouquet Le Paintour, de Faloise, qui congnut et confessa avoir eu et receu de homme sage et pourveu Regnaut Bigaut, viconte de Faloise, la somme de 110 soubz tournois qui deuz lui estoient, c'est assavoir

Pour avoir painté a huille une grant corne de cerf qui pent en la salle du manoir au viconte, $10 \mathrm{~s}$.

Item pour avoir mis huit piés de verrieres blanches, c'est assavoir 5 piés en la fenestre du hault de lad. salle prez la couverture d'icelle et 3 piez en la fenestre de la chambre dud. viconte et avoir relaiié les vielles vitres d'icelles fenestres et les avoir rassises, pour chascun pié 5 s., valent $40 \mathrm{~s}$. 
Item pour avoir fait certaines paintures en lad. salle, $10 \mathrm{~s}$.

Item pour la paine et sallaire de lui et d'un varlet qui furent par deux jours pour blanchir la chambre ou gist led. viconte, $10 \mathrm{~s}$.

Item pour avoir rappareillié et relaiié les verrieres de deux fenestres qui sont en la chappelle dud. chastel et y mectre environ deux piés de neuf verre, dont il lui ${ }^{\text {(a) }}$ a 1 pié de coullour et 1 pié de blant, et icelles rasseoir esd. fenestres en la sepmaine finee le $14^{\mathrm{e}}$ jour de decembre et en la sepmaine ensuivant, $40 \mathrm{~s}$.

De laquelle somme de 110 s. t. dessus dicte led. Fouquet se tint pour bien paié et en quicta le roy notre sire, led. viconte et touz autres; en tesmoing de ce ces lettres sont scellees du scel dessus duit, le $22^{\mathrm{e}}$ jour du mois de decembre l'an 1381.

(Signé:) GIROT DE M.

(a) Sic lui, au lieu de $y$.

\section{1391, après le 26 mars [Pâques].}

Extrait d'un rôle fragmentaire de travaux au château de Falaise.

A. Orig., parch., larg. 320 x haut. $340 \mathrm{~mm}$, texte sans doute inachevé (feuillet coupé dans sa partie supérieure); trou d'attache dans la marge gauche. BnF, ms fr. $26025, \mathrm{n}^{\circ} 1650$.

a. CHAve, Isabelle, Le château de Falaise (Calvados), étude préalable, Caen, C.R.M.H., 1999, dactyl., vol. III, nº 98.

INDIQUÉ: COUANON, Pascal, Le château de Falaise (Calvados), fouilles de sauvetage, Caen, S.R.A., 1986, dactyl., p. 20, nº 22.

[...]

A Robert Hue d'Aubigny ${ }^{(1)}$, pour l'achat de quatre pippes de caux vive par lui vendue a rendre a ses coux, une partie dedens les halles de Faloize et l'autre dedens le chastel, pour mesler avec autre caux morte qui estoit dedens led. chastel et aud. sablon pour faire mortier a couvrir la chappelle dud. chastel et les halles; pour ce par sa quittance rendue a court, $4 \mathfrak{E} \mathrm{t}$.

A Thomas Le Blant pour la vendue de 12 charetees de sablon et pour sa paine d'avoir porté plusieurs foiz chargié son benel de la caux dud. chastel es halles pour mesler avec la caux vive achatee dud. Robert Hue o avec (a) led. sablon, pour tout par sa quittance $4 \mathfrak{E} \mathrm{t}$.

A Laurens Paris et Yon Collas pour avoir recouvert en plusieurs lieux la chappelle dud. chastel environ Noel derrain passé et en especial en l'endroit de l'autel ou le prestre chantoit; laquelle avoit esté descouverte du clochier qui chey a terre par le bout de la nuit de Noel derrain passé et pour avoir semblablement recouvert sur le manoir ou le bailli est logié oud. 
chastel; item pour avoir recouvert l'apentis qui est a l'entree du donjon dud. chatel et pour avoir trouvé tout service a ce faire; pour tout $4 \mathfrak{E} \mathrm{t}$.

[...]

A Laurens Paris et Sanson Loisel pour une tasche de couverture de tieulle, c'est assavoir pour recouvrir de neuf a tache tout le gable de la chappelle du chastel de Faloize; item pour recouvrir de neuf a tache les cinq halles de Faloize, c'est assavoir les trois halles de devant la Trinité et les deux halles de devant Saint Gervez, ainsi que les ouvriers se trouveront tout service et les matieres qui sont rendues a place; ceste tasche demourant aux dessus diz pour $15 \mathfrak{E} \mathrm{t}$; ; pour ce, par leur quittance $15 \mathfrak{E} \mathrm{t}$.

A Colin Adam et Pierres Aubert pour leur paine d'avoir descouvert et mis a terre la tieulle qui estoit sur la vieille cuisine du tinel du chastel de Faloize, laquelle cuisine estoit commenchié a cheoir par pourreture, laquelle tieulle a esté remploié sur la chappelle du chastel et ailleurs en icellui, ou mestier estoit; pour ce par leur quittance 7 s. 6 d.

A Ricart Beauvallet, dignant, pour l'achat d'un seel de cuyvre pour mettre l'eaue benoite de la chappelle du chastel de Faloise, pour ce 16 s. t. [...]

(1) Aubigny: Calvados, arr. et cant. Falaise.

(a) Sic o avec, redondant.

\section{1391, 29 septembre - 1392, 14 avril [Pâques].}

Extrait d'un rôle de travaux menés au château de Falaise par Guillaume Le Diacre, vicomte de Falaise, pour le terme de Pâques 1392.

A. Orig., parch., larg. 340 x haut. 485 mm. BnF, ms fr. 26 025, n 1747.

a. CHave, Isabelle, Le château de Falaise (Calvados), étude préalable, Caen, C.R.M.H., 1999, dactyl., vol. III, n 102.

$[\ldots]$

A Fouquet Lempereur pour une taache ${ }^{(a)}$ de plommerie par lui prinse a faire oudit chastel, c'est assavoir pour avoir plommez tout de neuf les deux noz dedens lesquielz les eaues des goutieres descendent, pour eulz vuidier, qui contiennent 70 piés ou environ; item pour avoir levé le vieil plon des goutieres et pour avoir rassis neuf plon en lieu du vieil es quatre goutieres des grans salles et en celle de la chappelle et pour avoir remis en estat les plons des deux goutieres de la chambre de la Roine, le tout ou donjon du chastel de Faloize, et pour remettre en estat le pommel de plon qui est sur la porte jumelle de l'entree dud. chastel, ainsi que led. Fouquet sera tenu trouver tout charbon, toute soudeure et toute paine d'ouvriers; ceste taache ${ }^{(b)}$ a lui demourant pour le pris de $16 \mathfrak{E} \mathrm{t}$.

[...]

(a) (b) Sic taache. 
7. 1392 (n. st.), 11 avril.

Quittance de Colin Adam et Pierre Aubert, couvreurs, pour 7 s. 6 d. t. de travaux à la chapelle du château de Falaise.

A. Orig., parch., larg. $255 \mathrm{x}$ haut. $85 \mathrm{~mm}$, jadis scellé sur simple queue, trous d'attache dans la marge gauche. BnF, P.O. 8 Adam, $\mathrm{n}^{\circ} 2$.

a. CHAVE, Isabelle, Le château de Falaise (Calvados), étude préalable, Caen, C.R.M.H., 1999, dactyl., vol. III, nº 99.

INDIQUÉ: COUANON, Pascal, Le château de Falaise (Calvados), fouilles de sauvetage, Caen, S.R.A., 1986, dactyl., p. 20, nº 22.

A tous ceulx qui ces lettrez verront, Pierres Le Hursin, garde du seel des obligations de la viconté de Faloize, salut. Sachent que par devant Johan Roussel, commis soubz Jehan Levesque, tabellion juré et establi ou siege de Faloize, furent presens Colin Adam et Pierres Aubert, lesquelx congnurent avoir eu et receu de homme saige et pourveu Guillaume Le Dyacre, viconte de Faloize, la somme de sept soulz six deniers pour leur peine et salaire d'avoir descouvert une partie de la tieulle de dessus la vielle cuisine du tinel du chastel de Faloize pour icelle emploier sur la chapelle dud. chastel; de laquelle somme de $7 \mathrm{~s}$. $6 \mathrm{~d}$. t. dessus dicte les dessus diz se tindrent pour bien contens et paiez et en quitterent le roy notre sire, led. viconte de tous autres: en tesmoing de ce nous a la relation dud. tabellion avons mis a ces presentez le seel desd. obligations l'an 1391 le $11^{\mathrm{e}}$ jour d'avril (Signé avec paraphe:) J. LEVESQUE

\section{1399 (n. st.), avant le 26 janvier ${ }^{(1)}$.}

Devis de travaux de maçonnerie au château de Falaise, remporté par Raoul Bonjour, moins-disant.

A. Orig., parch., larg. $300 \mathrm{x}$ haut. $75 \mathrm{~mm}$, jadis scellé d'une simple queue sur repli, trois trous d'attache dans la marge gauche. B. L., Add. Ch. $11155^{(2)}$.

a. CHAve, Isabelle, Le château de Falaise (Calvados), étude préalable, Caen, C.R.M.H., 1999, dactyl., vol. III, nº 124.

Cy ensuit le devis d'une tasche de maconnerie ordonnee a estre faicte ou chastel de Faloise.

Et premierement pour reparer de neuf les allees d'entre la chappelle dud. chastel et le logeis du viconte de bon pavement de la carriere d'Aubigny de deux piez de long et de pié et demy ou environ et contiennent lesd. allees quarante et trois piez de long et huit piez et demy de 1 [a] y. Item pour refourmier de bonne piere de carrel trois des pilliers de lad. chappelle et aussi 
les pareiz d'icelle chappelle partout ou mestier sera de bonne pierre assise a mortier de caux et sera tenu l'ouvrier a doller et advister lesd. pierre et remettre en euvre le viel carrel qui est esd. allees et a soy trouver service et le roy trouvera carrel, caux et sablon a place.

Ceste tasche demoure a Raoul Bonjour, comme derrain encherisseur par le pris et somme de six livres dix soubz tournois.

(1) La quittance de Raoul Bonjour, maçon, en date du 26 janvier 1399 (n. st.), pour le montant de ces travaux fixe un terminus ante quem au devis. (2) Une mention dorsale signale: Purchased at Sotheby's. $12^{\text {th }}$ janv. 1856.

\section{1399 (n. st.), 26 janvier.}

Quittance de Raoul Bonjour, maçon, à Guillaume Le Diacre, vicomte de Falaise, pour $6 \mathfrak{E} 10$ s. t. de travaux à la chapelle du château de Falaise, en application du devis précédent.

A. Orig., parch., larg. 305 x haut. $60 \mathrm{~mm}$, jadis scellé sur simple queue, un trou d'attache dans la marge gauche. B. L., Add. Ch. $11393^{(1)}$.

a. CHAVE, Isabelle, Le château de Falaise (Calvados), étude préalable, Caen, C.R.M.H., 1999, dactyl., vol. III, n 123.

A tous ceulx qui ces lettres verront ou orront, Nicolas Houdin, clerc, garde du seel des obligations de la vicomté, salut. Sachent que par devant Robin Hays, tabellion, commis soubz Jehan Roussel, tabellion juré pour le roy notre sire ou siege de Faloise, fut present Raoul Bonjour, macon, lequel congneut et confessa avoir eu et receu de honnorable homme et sage Guillaume Le Dyacre, viconte de Faloise, la somme de six livres dix soulz tournois pour sa paine et salaire d'avoir faict et parfaicte la tasche de maconnerie, contenue ou devis ${ }^{(2)}$ parmy lequel ces presentes sont annexees; de laquelle somme de $6 \mathfrak{E} 10$ s. t. dessus dicte led. Bonjour se tint a bien paié et content et en quitta le roy notre sire, led. viconte et tous autres a qui quittance en peut et doit appartenir; en tesmoing de ce nous a la relation dud. tabellion avons mis a ces lettres le seel dessus dit sauf autrui droit; donné le 26e jour de janvier l'an 1398.

(Signé avec paraphe:) A. HAYs

(1) Une mention dorsale signale: Purchased at Moore's sale, $28^{\text {th }}$ April 1856.

(2) Voir supra $\mathrm{n}^{\circ} 8$.

\section{1405, 4 mai.}

Quittance de Jean Ragouget, fondeur de cloches de Sées (Orne), à Jean Aubert, vicomte de Falaise, pour $9 \mathfrak{E} 6$ s. 6 d. t. à lui payés pour la cloche neuve de la chapelle du château de Falaise, dont l'installation a été réceptionnée par Robert Delaunoy, maître des auvres du roi de la vicomté de Falaise.. 
A. Orig., parch., larg. $265 \mathrm{x}$ haut. $150 \mathrm{~mm}$, jadis scellé sur simple queue, trou d'attache au milieu de la marge gauche. BnF, ms fr. 26034 , $\mathrm{n}^{\circ} 3716^{(1)}$.

a. CHAve, Isabelle, Le château de Falaise (Calvados), étude préalable, Caen, C.R.M.H., 1999, dactyl., vol. III, nº 129.

A tous ceulx qui ces lettres verront ou orront, Nicolas Houdin, prestre, garde du seel des obligations de la viconté de Faloise, salut. Savoir faisons que par devant Perrin Dupont, clerc, commis soubz Thomas Marie, clerc, tabellion du roy notre sire juré ou siege de Faloise, fut present en sa personne Jehan Ragouget, saintier demourant a Sees, qui congnut et confessa avoir eu et receu de homme saige et pourveu Jehan Auber, viconte de Faloise, la somme de neuf livrez cinq soulz six deniers tournois qui deue luy estoit, c'est assavoir pour une cloche neufve pesant cinquante cinq livrez de metal bon et suffisant par luy faicte, vendue, livree, mise et assise en la chappelle du chastel de Faloise, en lieu d'une autre qui en lad. chappelle avoit esté prinse pour sonner le gaet ${ }^{\text {(a) }}$ dud. chastel, par le prix de deux soulz six deniers chascune livre, vallent six livres dix sept soulx six deniers tournois, et pour une autre cloche pesant cinquante huit livres de metal bon et suffisant par luy vendue, livree, mise et asssise ou autrefoiz a acoustumé estre pour sonner led. guet, par le prix dessus dit vault sept livres et cinq soulz tournois ou lieu de celle devant dicte, laquelle estoit cassee tout au lont et ne povet plus sonner, laquelle luy a esté baillié en paiement de deux soulz tournois pour livre et a esté trouvee peser quarante huit livres et demie, vault quatre livres dix sept soulz, ainsi reste lad. somme de neuf livres six soulz six deniers tournois; de laquelle somme il se tint a bien poié et en quitta le roy notre sire, led. viconte et tous autrez a qui quitance en peut et doibt appartenir. Present adce Robert Delaunoy, maistre des euvres du roy notre dit seigneur en lad. viconté, qui temoingna en verité toutes les choses dessus dictes estre vraies et avoir esté faictes et livrees par les pris dessus diz et ainssy que dit est dessus; en tesmoing de ce ces lettres sont seellees du seel dessus dit sauf autrui droit. Ceu fut fait le $4^{\mathrm{e}}$ jour de may l'an mil quatre cens et cinq. (Signé avec paraphe:) DUPONT

(1) Une mention dorsale signale: Purchased at Moore's sale, $28^{\text {th }}$ April 1856. (a) Sic.

\section{1407, 4 septembre.}

Extrait d'une quittance de Thomas Chappon et Guillaume Jouenne, maçons, au nom de Jacques Marc, terrassier bionnier et de Bertin Lebret, valet de bras, à Nicolas Potier, vicomte de Falaise, pour 76 s. t. de travaux de maçonnerie au château de Falaise. 
A. Orig., parch., larg. 270 x haut. $215 \mathrm{~mm}$, jadis scellé sur simple queue, trou d'attache au milieu de la marge gauche. BnF, ms fr. $26035, n^{\circ} 3963$.

a. Chave, Isabelle, Le château de Falaise (Calvados), étude préalable, Caen, C.R.M.H., 1999, dactyl., vol. III, nº 135.

$[\ldots]$

Item pour avoir maconné soubz les solles du prosnel de devant la chappelle et avoir fait un contrefeu en la chappelle ou gist le chappelain de lad. chappelle. $[\ldots]$

\section{1407,2 octobre.}

Quittance de Pierre Le Miere, marchand de tuiles, à Nicolas Potier, vicomte de Falaise, pour $29 £ 5$ s. t. de vente et de transport au château de 13000 tuiles, utilisées notamment pour la chapelle castrale, réceptionnées par Robert Delaunoy, maître des oeuvres du roi en la vicomté de Falaise.

A. Orig., parch., larg. $305 \mathrm{x}$ haut. $90 \mathrm{~mm}$, jadis scellé sur simple queue, deux trous d'attache au milieu de la marge gauche. BnF, ms fr. 26035 , $\mathrm{n}^{\circ} 3972$.

a. Chave, Isabelle, Le château de Falaise (Calvados), étude préalable, Caen, C.R.M.H., 1999, dactyl., vol. III, nº 136.

INDIQUÉ: Arch. dép. Seine-Maritime, 16 F 25, papiers Henri de Frondeville.

A touz ceulx qui ces presentes lettres verront ou orront, Nicolas Houdin, prestre, garde du scel des obligations de la viconté de Faloise, salut. Savoir faisons que par devant Perrin Dupont, clerc, commis soubz Jehan Roussel, clerc, tabellion du roy notre sire juré ou siege de Faloise, fut present Pierres Le Miere, marchant de tuille, demourant en la paroisse de Barbery, qui congnut et confessa avoir eu et receu de homme pourveu et saige Nicolas Potier, viconte de Faloise, la somme de vingt et neuf livres cinq soulz tournois, qui deue luy estoit pour la vendue de treze milliers de tuille, a $45 \mathrm{~s}$. t. le millier, vallant lad. somme de $29 £ 5$ s. t. par luy vendue, livree et rendue ou chastel de Faloise depuis la feste de Saint Jehan Baptiste derrain passee, pour mectre et emploier es reparations dud. chastel tant sur les fours et tourelles que sur les maisons et chapelle d'icelluy lieu et aussy sur les halles d'empres l'eglise de la Trinité de Faloise, sur les moulins le roy seans soubz le donjon d'icelluy chastel et sur les maisons des prisons du roy notre sire; de laquelle somme de $29 \mathfrak{£} 5$ s. t. dessus dicte led. Le Miere se tinst pour bien paié et content et en quicta le roy notre sire, led. viconte et tous autres a qui quictance en appartient. Present adce Robert Delaunoy, a present maistre des œuvrez du roy notre sire en lad. viconté, qui tesmoingna et afferma que par led. Le Miere lad. tuille avoit esté rendue et apportee 
oud. chastel et que cousté en avoit le prix dessus desclairé; en tesmoing de ce, ces lettres sont scellees du seel dessus dit sauf autruy droit. Ce fut fait le $2^{\mathrm{e}}$ jour d'octobre l'an 1407.

\section{1407,13 novembre.}

Quittance de Thomas Le Blant, voiturier de Falaise, à Nicolas Potier, vicomte de Falaise, pour 20 s. t. de transport de pierre de taille devant la chapelle du château de Falaise.

A. Orig., parch., larg. $285 \mathrm{x}$ haut. $85 \mathrm{~mm}$, jadis scellé sur simple queue, trou d'attache au milieu de la marge gauche. BnF, ms fr. 26 035, $\mathrm{n}^{\circ} 3986$.

a. CHAVE, Isabelle, Le château de Falaise (Calvados), étude préalable, Caen, C.R.M.H., 1999, dactyl., vol. III, nº 138.

A touz ceulx qui ces lettres verront ou orront Nicolas Houdin, prestre, garde du seel des obligations de la viconté de Faloise, salut. Savoir faisons que par devant Jehan Rouxel, clerc, tabellion du roy notre sire juré ou siege de Faloise, fut present Thomas Le Blant, voiturier demourant a Faloise, qui congnut et confessa avoir eu et receu de homme pourveu et saige Nicolas Potier, viconte de Faloise, la somme de vingt soulz tournois pour l'admenaige d'un quarteron de pierre appellé carrel, que il avoit admené ou chastel de Faloise devant la chappelle et la porte de la court dud. viconte, pour lors que Jehan Aubert estoit viconte dud. lieu de Faloise et par le commandement d'icellui pour emploier es œuvres d'icelluy chastel; pour laquelle voiture et admenage led. Auber n'avoit aucune chose paié aud. Thomas, si comme il appert par une cedulle signee du saing manuel dud. Aubert ${ }^{(1)} \mathrm{a}$ laquelle ces presentes sont annexees; de laquelle somme ${ }^{(a)}$ de 20 s. t. dessus dicte led. Thomas se tinst pour bien paié et content et en quicta le roy notre sire, led. viconte et touz autres a qui quictance en apartient; en tesmoing de ce ces presentes sont scellees du seel dessus dit sauf autry droit. Ce fut fait le 13e jour de novembre l'an 1407.

(Signé avec paraphe:) RousseL

(1) Document disparu.

(a) de laquelle somme, répété par erreur.

\section{1407, 21 décembre.}

Extrait d'une quittance de Robert Delaunoy, charpentier des ouvres $d u$ roi, maître et visiteur des œuvres du roi de la vicomté de Falaise, à Nicolas Potier, vicomte de Falaise, pour $21 £ 11$ s. t. pour travaux de charpenterie au château de Falaise. 
A. Orig., parch., larg. $285 \mathrm{x}$ haut. $180 \mathrm{~mm}$, jadis scellé sur simple queue. BnF, ms fr. 26 035, nº 3998.

a. Chave, Isabelle, Le château de Falaise (Calvados), étude préalable, Caen, C.R.M.H., 1999, dactyl., vol. III, nº 140.

$[\ldots]$

Et premierement pour avoir ouvré et aidié a faire les portez des halles a blé se [a] ntes pres l'eglise de Saint Gervés de Faloise, ou portal de la chappelle du chastel de Faloise qui de nouvel a esté fait, pour icelluy avoir laté et contrelaté, couvert d'essende, pour avoir refait la roe du puiz, mis rouiz jointiz ou il en failloit sur icelluy, et planchié tout de neuf, planchié une partie du pont dormant par devers la ville de gros carreaulx de boys de troys doys d'espace.

[...]

\section{1408, 3 mai.}

Extrait d'une quittance de Drouet Després, serrurier de Falaise, à Nicolas Potier, vicomte de Falaise, pour 66 s. 6 d. t. de travaux au château de Falaise.

A. Orig., parch., larg. 255 x haut. $155 \mathrm{~mm}$, jadis scellé sur simple queue, un trou d'attache dans la marge gauche. BnF, P.O. 2352 Potier en Normandie, $\mathrm{n}^{\circ} 20$.

a. CHAVe, Isabelle, Le château de Falaise (Calvados), étude préalable, Caen, C.R.M.H., 1999, dactyl., vol. III, nº 142.

$[\ldots]$

Item pour le rappareil d'un huys de fer qui est en la chappelle du danjon, lequel estoit tout depechié et le tourouil et serreure rompuz et cloué de groz clous a teste par dehors, $15 \mathrm{~s}$.

[...]

Item pour un chandelier mis en la chappelle du chastel, $15 \mathrm{~d}$.

$[\ldots]$

\section{1414,29 octobre.}

Extrait d'une quittance de Drouet Després, serrurier de la paroisse Saint-Gervais de Falaise, à Jean Monnet, vicomte de Falaise, pour 61 s. t. de travaux de serrurerie au château de Falaise.

A. Orig., parch., larg. 250 x haut. $165 \mathrm{~mm}$, jadis scellé sur simple queue; angle inférieur droit lacunaire. BnF, ms fr. 26 040, n 4896.

a. CHAVE, Isabelle, Le château de Falaise (Calvados), étude préalable, Caen, C.R.M.H., 1999, dactyl., vol. III, nº 154. 
$[\ldots]$

Pour une clef pour le sacraire de la chappelle du chastel de Faloise, 10 d. t.

$[\ldots]$

17. 1423 (n. st.), $1^{\text {er }}$ mars.

Extrait d'un rôle des travaux menés par Drouet Després, serrurier, au château

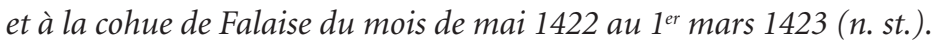

A. Orig., parch., larg. $320 \mathrm{x}$ haut. $265 \mathrm{~mm}$, jadis scellé sur simple queue avec repli, trou d'attache dans l'angle inférieur gauche. BnF, nouv. acq. fr. $20147, \mathrm{n}^{\circ} 13$.

a. Chave, Isabelle, Le château de Falaise (Calvados), étude préalable, Caen, C.R.M.H., 1999, dactyl., vol. III, nº 170.

$[\ldots]$

Item pour 18 verges de fer qui furent mises en la chapelle du belle dud. chastel pour tenir le verre d'icelle chappelle dont il lui en n'y a ${ }^{(a)}$ quatre grigneurs que les aultres, chascune verge a $12 \mathrm{~d}$., vallent en somme $18 \mathrm{~s}$; ; pour ce $18 \mathrm{~s}$.

$[\ldots]$

(a) Sic.

18. 1424 (n. st.), après le $1^{\text {er }}$ mars.

Extrait d'un rôle des travaux menés par Drouet Després, serrurier, au château de Falaise, à compter du 25 mars 1424 (n. st). La quittance de Drouet Després à Girard d'Esquay, vicomte de Falaise, pour le montant de ces travaux est délivrée le 29 août $1425^{(1)}$.

A. Orig., parch., larg. 195 x haut. $300 \mathrm{~mm}$, jadis scellé sur simple queue, trou d'attache dans la marge gauche. BnF, ms fr. 26 047, nº 227.

a. Chave, Isabelle, Le château de Falaise (Calvados), étude préalable, Caen, C.R.M.H., 1999, dactyl., vol. III, nº 179.

$[\ldots]$

Item pour la chappelle du danjon, es prisons qui sont desoubz lad. chappelle, pour refaire ung huiz de fer que feu Larde ou ceulx qui tenoient pour lui, depecherent, dont le tiers d'ycelluy huiz de fer fut refait, et pour ung gonst pour led. huiz avesques une clef et regarnis la serrure dud. huiz tout de neuf; pour ce $25 \mathrm{~s}$.

$[\ldots]$

(1) $\mathrm{BnF}$, ms fr. $26048, \mathrm{n}^{\circ} 455$. 
19. 1430 (n. st.), 22 mars.

Extrait d'une quittance de Perrin Le Breton, Robin Frellon et Guillaume Loisel, couvreurs de tuiles, à Girard d'Escay, vicomte de Falaise, pour $10 \mathfrak{E} 15$ s. 10 d. t. de travaux de couverture au château de Falaise, sous la conduite de Jean du Moustier, maître des cuvres du roi de la vicomté de Falaise.

A. Orig., parch., larg. $270 \mathrm{x}$ haut. $165 \mathrm{~mm}$, jadis scellé sur simple queue; deux trous d'attache dans la marge gauche. BnF, ms fr. 26053 , $\mathrm{n}^{\circ} 1299$.

a. Chave, Isabelle, Le château de Falaise (Calvados), étude préalable, Caen, C.R.M.H., 1999, dactyl., vol. III, n 186.

[...]

Item pour avoir recouvert sur le grenier de la chapelle ou sont les blés du cappitaine dud. chastel.

[...]

\section{1433, 18 août.}

Extrait d'une quittance de Guillaume Le Heurteur, Colin Pierre et Jean Chevalier, charpentiers, à Jean Seynt, vicomte de Falaise, pour $17 \mathfrak{E}$ t. de travaux de charpenterie au château de Falaise, sous la conduite de Jean du Moustier, maître des cuvres du roi de la vicomté de Falaise.

A. Orig., parch., larg. 340 x haut. 265 mm, jadis scellé sur simple queue. BnF, ms fr. $26057, \mathrm{n}^{\circ} 2128$.

a. CHAve, Isabelle, Le château de Falaise (Calvados), étude préalable, Caen, C.R.M.H., 1999, dactyl., vol. III, nº 192.

[...]

Item pour avoir fait ung caril a lit en la chambre de derriere la chappelle; pour ce, ung jour.

[...]

\section{1434, 17 décembre.}

Extrait d'une quittance de Julliot Le Gautier et Robin du Vivier, ouvriers de bras, à Jean Seynt, écuyer, ancien vicomte de Falaise, pour $9 \mathfrak{£}$ t. de travaux au château de Falaise, réceptionnés par Jean du Moustier, maître des ouvres du roi de la vicomté de Falaise.

A. Orig., parch., larg. 250 x haut. $155 \mathrm{~mm}$, jadis scellé sur simple queue, trou d'attache dans la marge gauche. BnF, ms fr. 26 058, nº 2417. 
a. CHAve, Isabelle, Le château de Falaise (Calvados), étude préalable, Caen, C.R.M.H., 1999, dactyl., vol. III, nº 195.

[...]

Et premierement pour avoir servy les macons qui ont reparé ung costé de la maison des haultes salles dud. chastel par devers les estables de la barbequenne et fait ung coing de carrel tout de neuf en icellui costé et maconné pluseurs breches qui estoent aupres d'icellui coing et a avoir maconné deux querneaulx aupres de la grosse tour et dessoubz les solles du portal de la chappelle et en pluseurs autres lieux ou lesd. macons ont maconné comme plus a plain est faicte mention en la quittance desd. macons passee aujourduy par Jamet Aillot ${ }^{(1)}$.

$[\ldots]$

(1) Document disparu.

\section{1441, 8 juillet.}

Extrait d'une quittance de Jamet Aillot, maçon, au nom de Perrin Vallée, Jean Pichon, Etienne Lermynier, aussi maçons, à Guillaume Plompton, écuyer, vicomte de Falaise, pour $6 \mathfrak{E} 13$ s. 4 d.t. de travaux de maçonnerie au château de Falaise, réceptionnés par Guillaume Le Heurteur, maître des œuvres du roi de la vicomté de Falaise.

A. Orig., parch., larg. $305 \mathrm{x}$ haut. $135 \mathrm{~mm}$, jadis scellé sur simple queue. BnF, P.O. 2305 Plompton, $n^{\circ} 4$.

a. CHAve, Isabelle, Le château de Falaise (Calvados), étude préalable, Caen, C.R.M.H., 1999, dactyl., vol. III, n 204.

[...]

Et premierement pour avoir refait ung sieul en la chambre de desoubz la chappelle du danjon, lequel estoit depecié par pourricture.

[...]

\section{1442 (n. st.), 5 février.}

Extrait d'une quittance de Robin Desqay, serrurier, à Guillaume Plompton, écuyer, vicomte de Falaise, pour 105 s. t. de travaux au château et à la geôle de Falaise.

A. Orig., parch., larg. 225 x haut. $230 \mathrm{~mm}$, jadis scellé sur simple queue; pièce mutilée et texte effacé dans l'angle inférieur droit. BnF, ms fr. $26068, n^{\circ} 4225$.

a. Chave, Isabelle, Le château de Falaise (Calvados), étude préalable, Caen, C.R.M.H., 1999, dactyl., vol. III, nº 207. 
$[\ldots]$

Item 1 serreure $[\ldots]^{(a)}$ de la chappel dud. chastel pour mettre les ornemens a chanter la messe; pour ceu, 12 s. 6 [d.]

$[\ldots]$

(a) Deux ou trois mots illisibles, faisant référence sans doute à des coffres ou des placards.

\section{1445,15 septembre.}

Extrait d'une quittance de Tibault Katerine et Jean Aubert, maçons, au nom de Colin Berrart, Robert Goubin, Guillot Potier, Robin Le Cheron, Jean Dupont et Perrin Bochier, aussi maçons, à Guillaume Plompton, écuyer, vicomte de Falaise, pour $8 \mathfrak{E} 3$ s. 4 d. t. de travaux au château de Falaise, réceptionnés par Guillaume Le Heurteur, maître des cuvres du roi de la vicomté de Falaise.

A. Orig., parch., larg. $265 \mathrm{x}$ haut. $160 \mathrm{~mm}$, jadis scellé sur simple queue, deux trous d'attache dans la marge gauche. Arch. dép. Calvados, coll. Danquin, F 1379 (3).

a. CHAVE, Isabelle, Le château de Falaise (Calvados), étude préalable, Caen, C.R.M.H., 1999, dactyl., vol. III, nº 215.

$[\ldots]$

Item pour avoir maconnee soubz une solle de bois assises es galleries de devers la chappelle.

$[\ldots]$

\section{1445,26 septembre.}

Extrait d'une quittance de Robin Cesnye, serrurier, à Guillaume Plompton, écuyer, vicomte de Falaise, pour 101 s. 2 d. t. de travaux de serrurerie au château de Falaise, réceptionnés par Guillaume Le Heurteur, maître des cuvres du roi de la vicomté de Falaise.

A. Orig., parch., larg. 280 x haut. $205 \mathrm{~mm}$, jadis scellé sur simple queue, trou d'attache dans la marge gauche. BnF, P.O. 2305 Plompton, no 8 .

a. CHAVE, Isabelle, Le château de Falaise (Calvados), étude préalable, Caen, C.R.M.H., 1999, dactyl., vol. III, nº 216.

$[\ldots]$

Item a l'uys des greniers de dessus la chappelle, une serrure; pour ce $7 \mathrm{~s}$.

$[\ldots]$

Item a l'uys venant de la salle a la cuisine, ung toureil tout cy de $20 \mathrm{~d}$., et a l'uys de la chapele du danjon, avoir fait la clef, auberon et exilles, pour ce $10 \mathrm{~s}$. 
26. 1445,3 novembre.

Extrait d'une quittance de Perrin Hue, Jean Guillaumin, Jacquet Pisson, manouvres, au nom de Jean Le Vavasseur, Michel Olivier, Jean Tubelaine, Gautier Sonate, Guillaumin Girouart, Perrin Le Bouvier, Jean Le Moigne, Perrin Leroy, aussi manouvres, à Guillaume Plompton, écuyer, vicomte de Falaise, pour $12 \mathfrak{£} 17$ s. 6 d. de travaux au château de Falaise, réceptionnés par Guillaume Le Heurteur, maître des ouvres du roi de la vicomté de Falaise.

A. Orig., parch., larg. 270 x haut. $200 \mathrm{~mm}$, jadis scellé sur simple queue, trou d'attache dans la marge gauche. BnF, ms fr. $26074, \mathrm{n}^{\circ} 5346$.

a. CHAVE, Isabelle, Le château de Falaise (Calvados), étude préalable, Caen, C.R.M.H., 1999, dactyl., vol. III, n² 219.

[...]

Item pour avoir servy les massons tant de tuille, de mortier que de late, qui ont couvert une luquenne du costé de la grant maison et couvert sur les allees de anpres de la chapele.

$[\ldots]$

27. 1455 (n. st.), 24 mars.

Extrait d'une quittance de Martin Le Petit et Raoullin Féret, manouvres, au nom de Jean de Fié, aussi manouvre, à Guillaume Lachère, écuyer, vicomte de Falaise, pour 68 s. 9 d. t. de travaux au château de Falaise, réceptionnés par Perrin Thomine, maître des œuvres du roi à Falaise.

A. Orig., parch., larg. $350 \mathrm{x}$ haut. $145 \mathrm{~mm}$, jadis scellé sur simple queue. BnF, P. O. 1407 Grésille, nº 14.

a. CHAve, Isabelle, Le château de Falaise (Calvados), étude préalable, Caen, C.R.M.H., 1999, dactyl., vol. III, n² 228.

$[\ldots]$

C'est assavoir pour avoir servy les massons qui ont fais et assis les entablemens de la chappelle du chastel dud. Faloise et reffait et remparé ung des pilliers d'icelle chappelle et aussi ung des gables du grant fenil d'icellui chastel.

$[\ldots]$

28. 1459 (n. st.), 14 février.

Extrait d'une quittance de Robin Janvret, charretier, à Guillaume Lachère, vicomte de Falaise, pour $15 \mathfrak{E} 6$ s. de travaux au château de Falaise, réceptionnés par Pierre Thomine, maître des œuvres du roi de la vicomté de Falaise. 
A. Orig., parch., larg. 340 x haut. 295 mm, jadis scellé sur simple queue, deux trous d'attache dans la marge gauche. BnF, fr. $26085, n^{\circ} 7244$.

a. CHAve, Isabelle, Le château de Falaise (Calvados), étude préalable, Caen, C.R.M.H., 1999, dactyl., vol. III, nº 233.

$[\ldots]$

Item a avoir repparé les chambres du retrait des salles d'empres la chappelle du chastel.

[...]

Item une grant breche qui estoit ou mur de l'allee d'entre la salle d'anpres de la chappelle et la cuisine d'empres la cave.

[...]

Item a refaire deux des sieges de lad. chappelle.

[...]

Item aussi partie dud. sablon a esté employé a faire tout le mortier [...] qu'il a convenu employer ou fait des couvertures de tuille et es doubliers desd. couvertures faictes [...] [sur] les salles d'anpres de la chappelle tant d'un costé que d'autre, le four, la cuisine et les autrez maisons et les galleries tenantes a icelle, les quatre tours de devers la ville et aussi les corniers assiz sur icelles.

$[\ldots]$ 


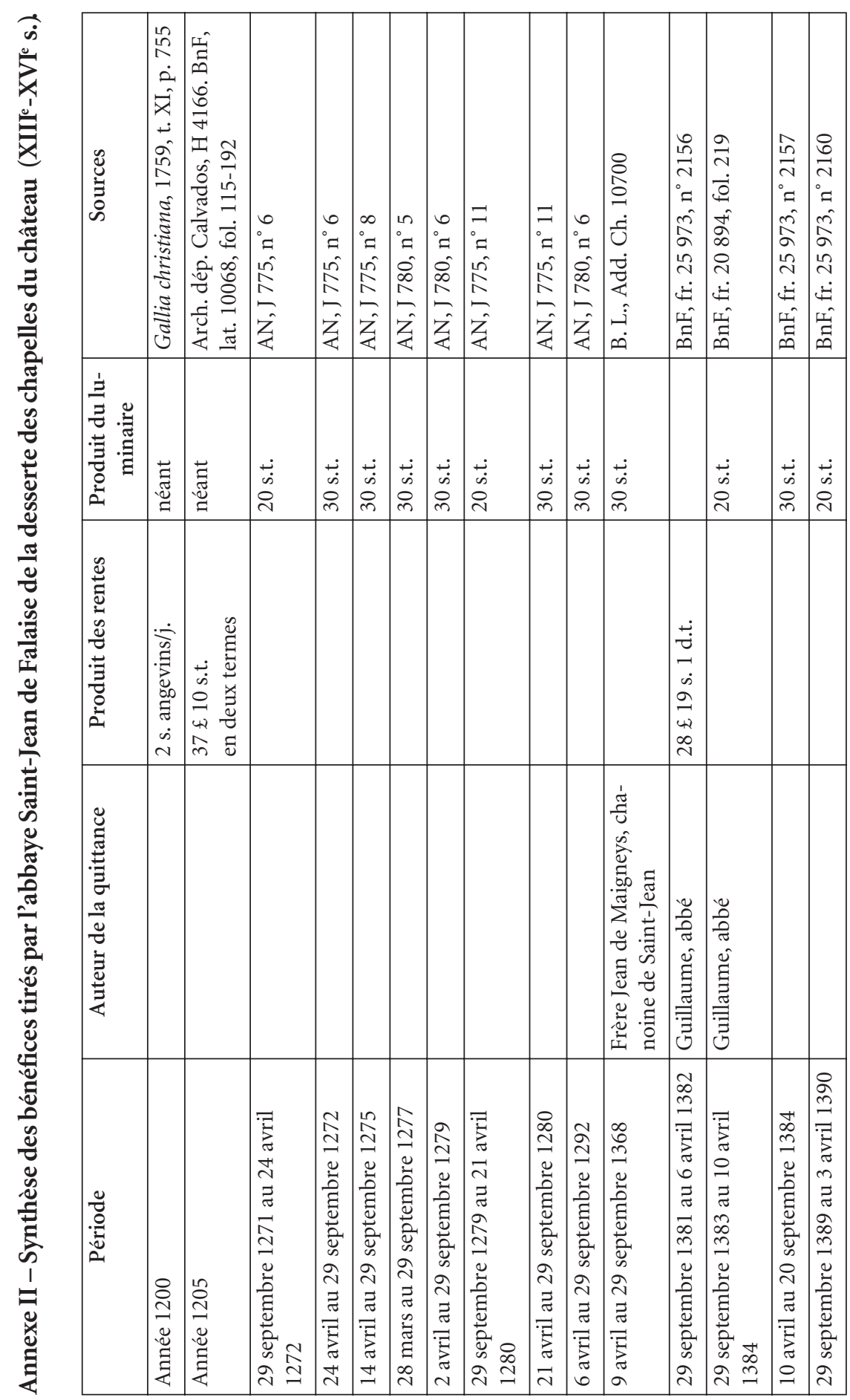




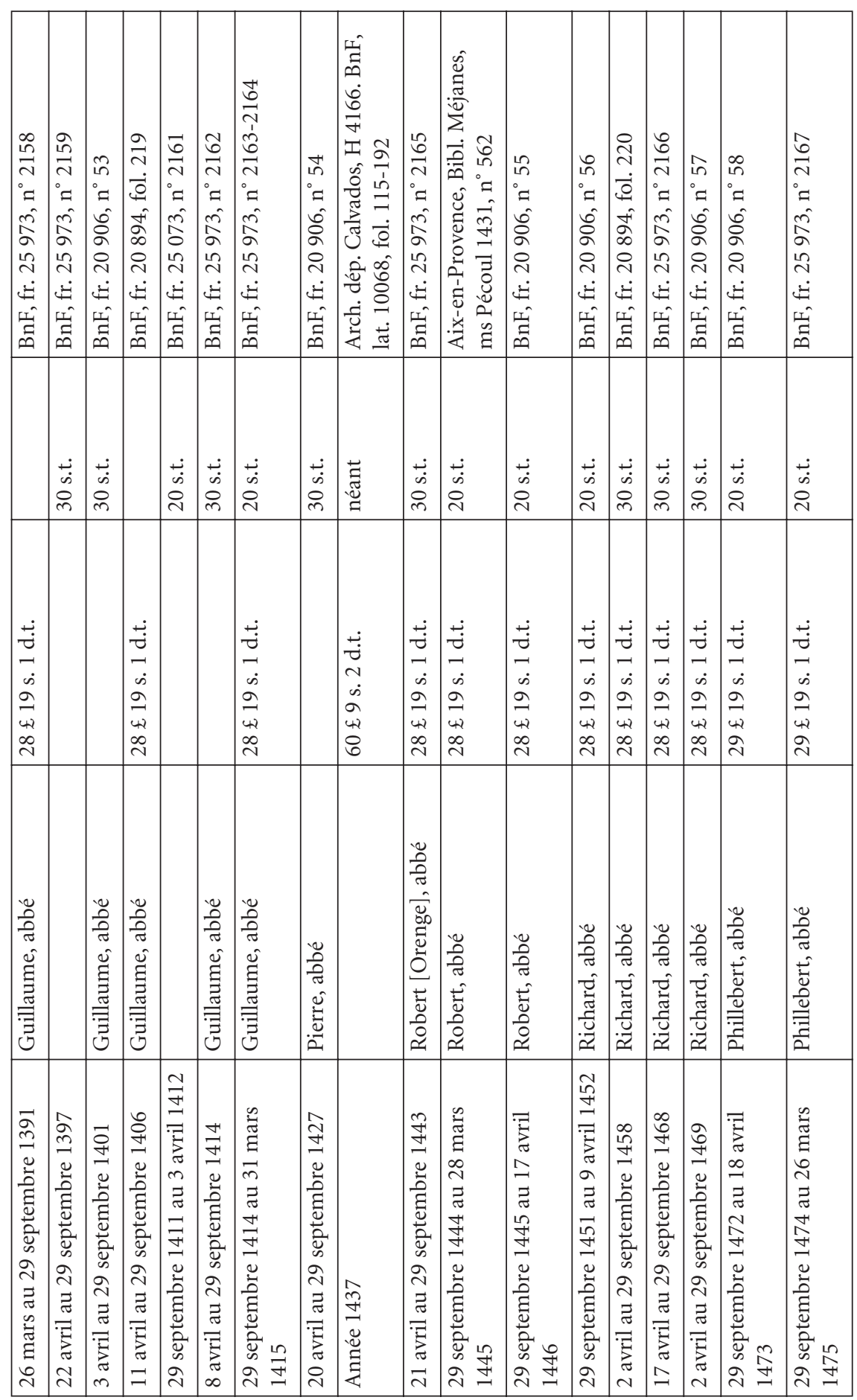




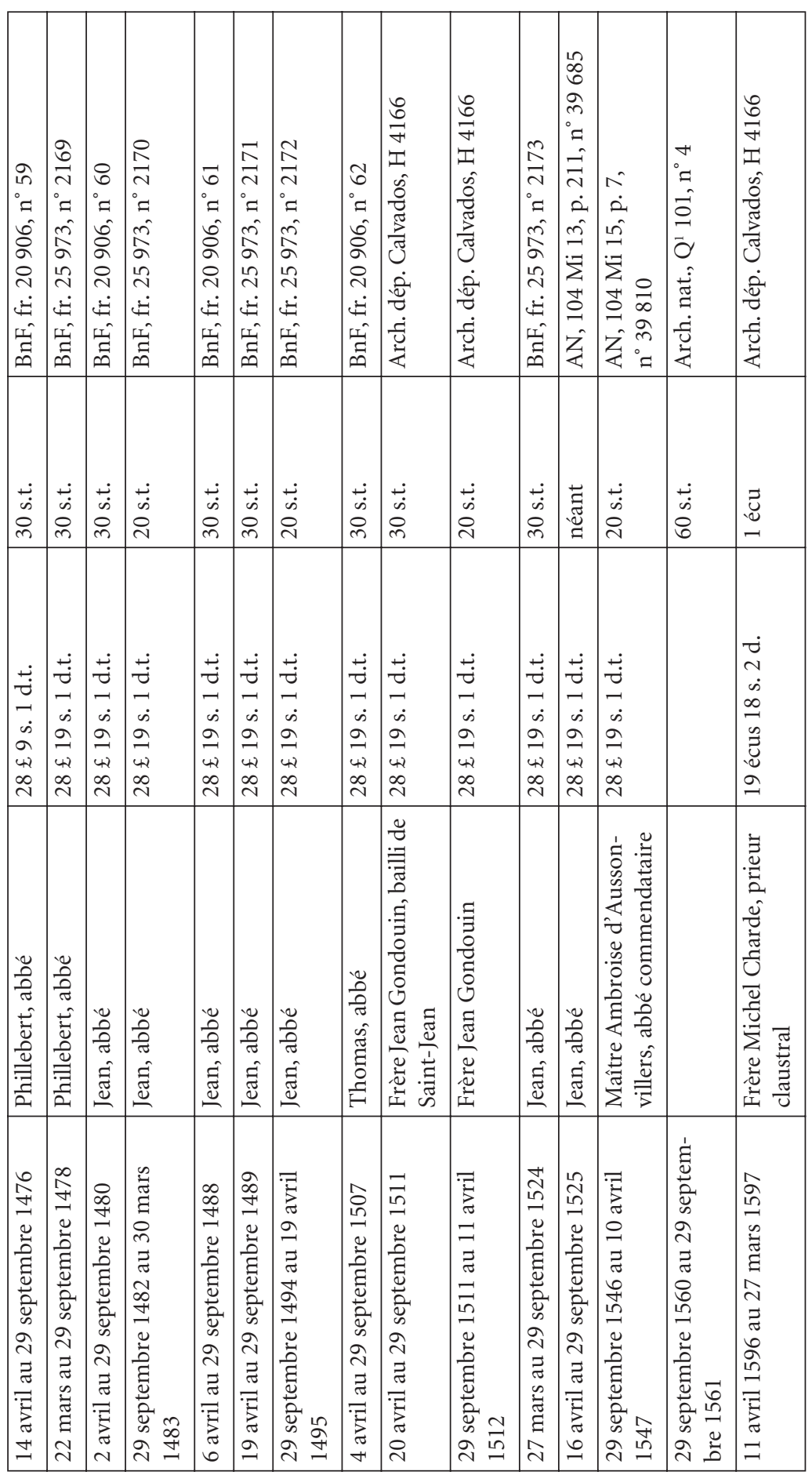




\section{Annexe III - Illustrations}

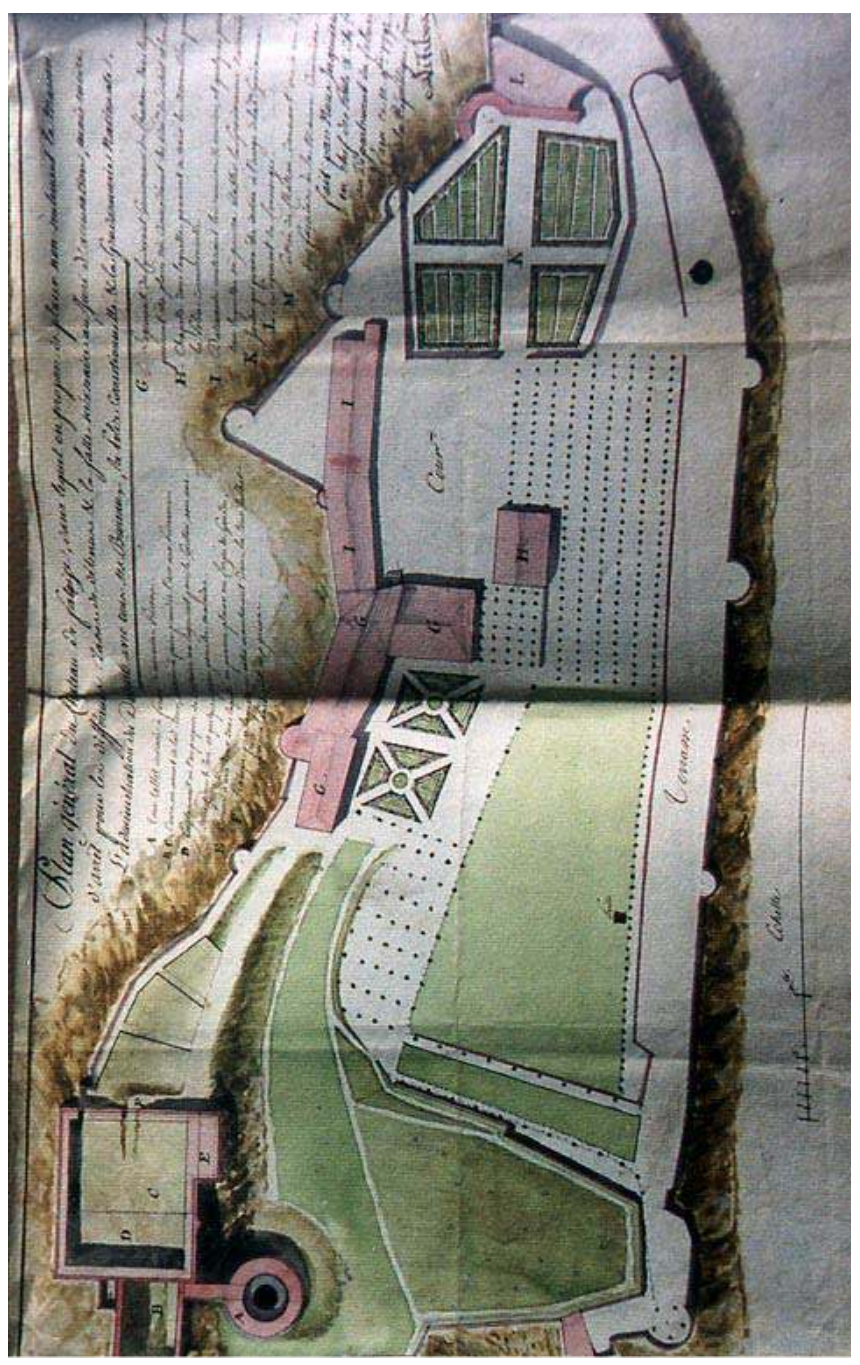

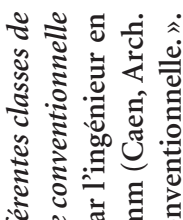

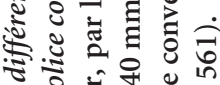

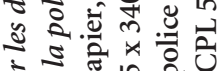

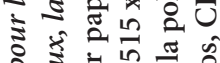

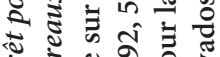

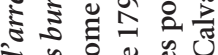

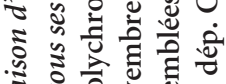

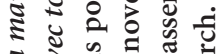

डิ

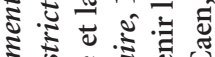

蛋

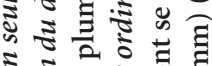

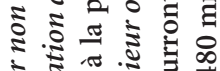

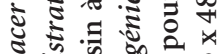

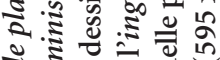

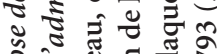

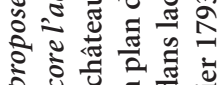

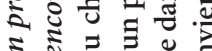

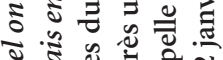

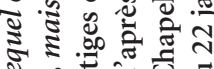

ङ

है

ज记

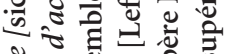

.

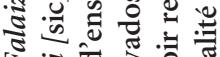

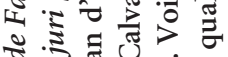

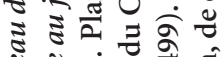

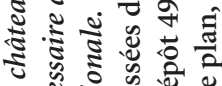

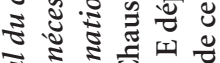

एँ

ष्ञ

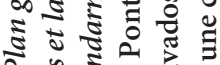

원

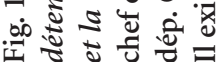




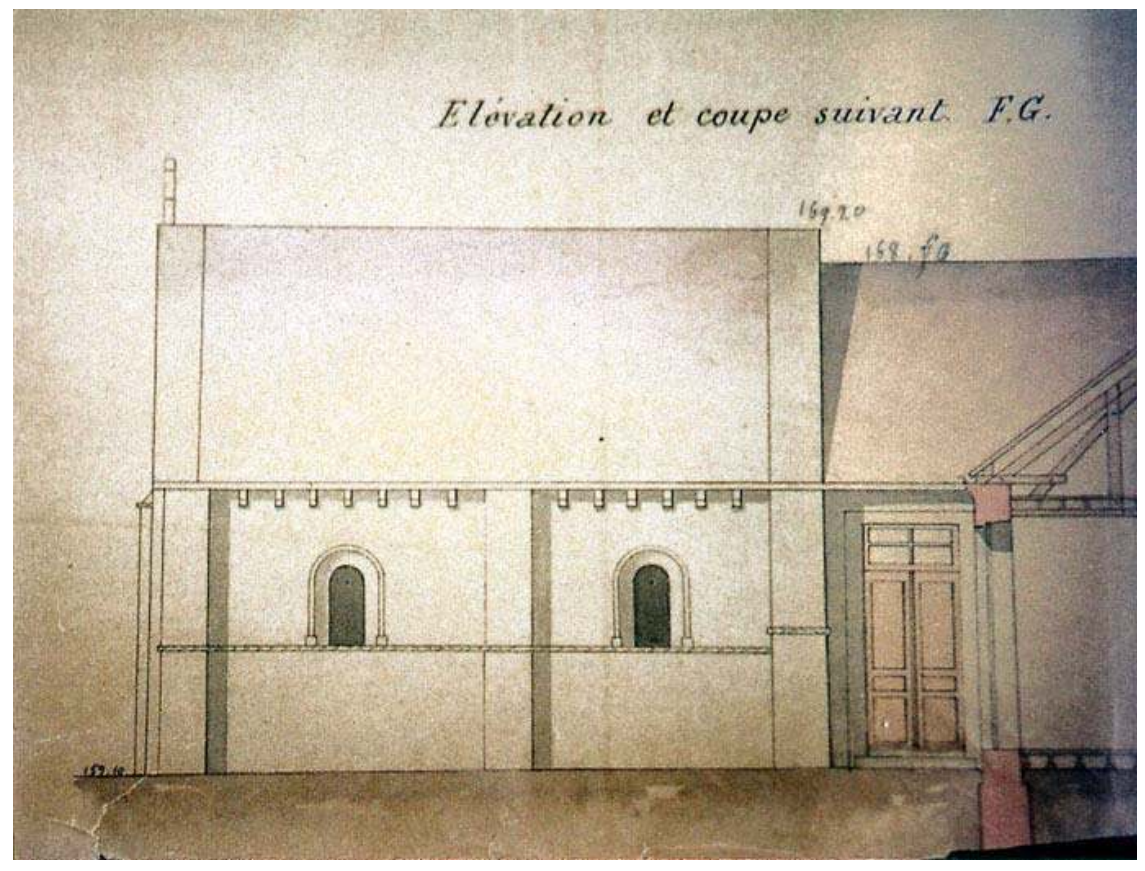

Fig. 2 : Plan et élévation nord du chœur de la chapelle castrale. Dessin à la plume et lavis polychrome sur papier, par Carayon, 30 août 1881 . Éch. de $0,01 \mathrm{~m} / \mathrm{m}$. Caen, Arch. dép. Calvados, 386 E dépôt 491.

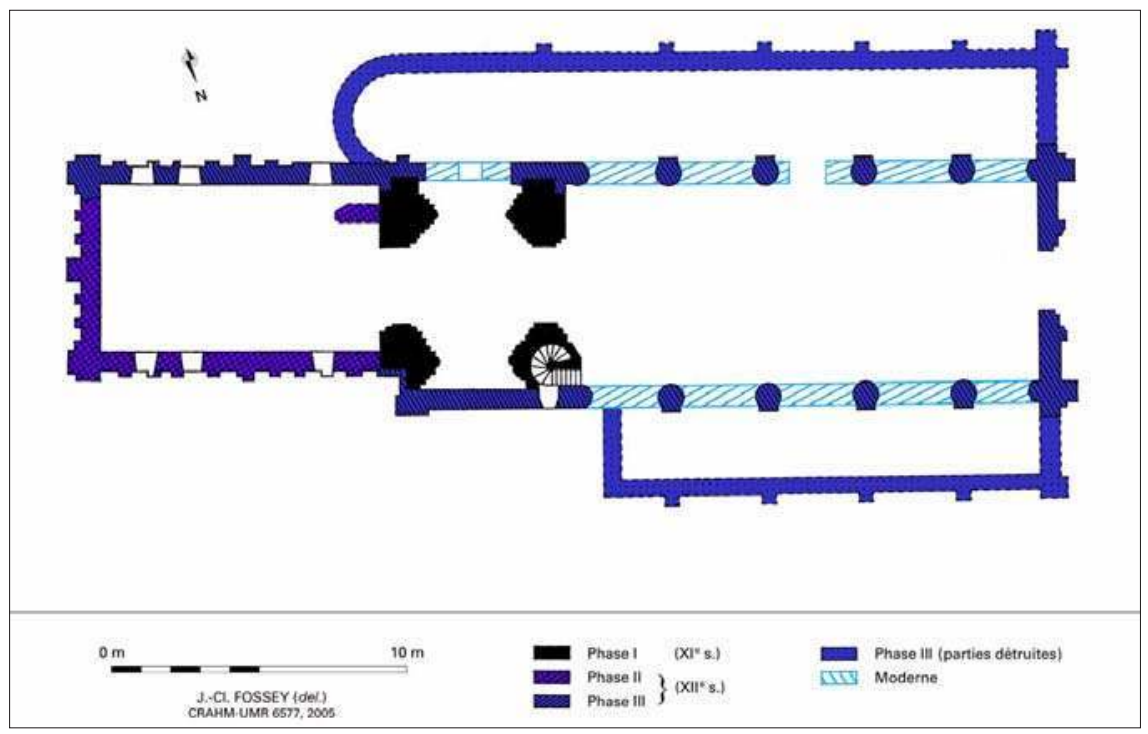

Fig. 3 : Plan de l'église de Thaon, redessiné par Jean-Claude Fossey, à partir d'un relevé publié par Lucien Musset [MUSSET, 1987, p. 120]. 

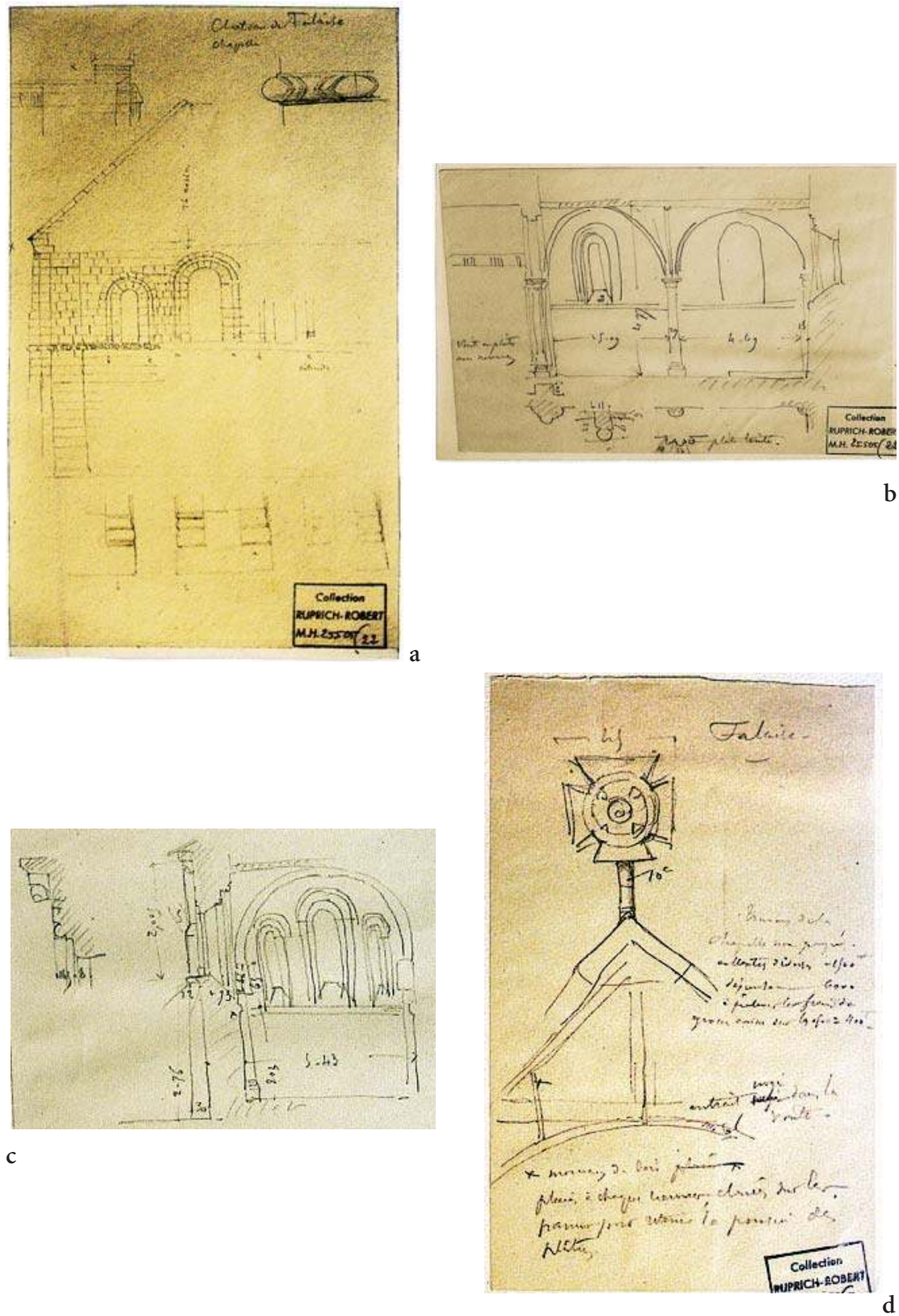

Fig. 4 (a, b, c, d) : Élévations et vestiges de l'ornementation de la chapelle castrale. Sept croquis au crayon noir sur papier, par Victor Ruprich-Robert, 1869. Sans éch. Paris, Méd. du Patrimoine, archives de la Commission des Monuments historiques, 25 505/22. 


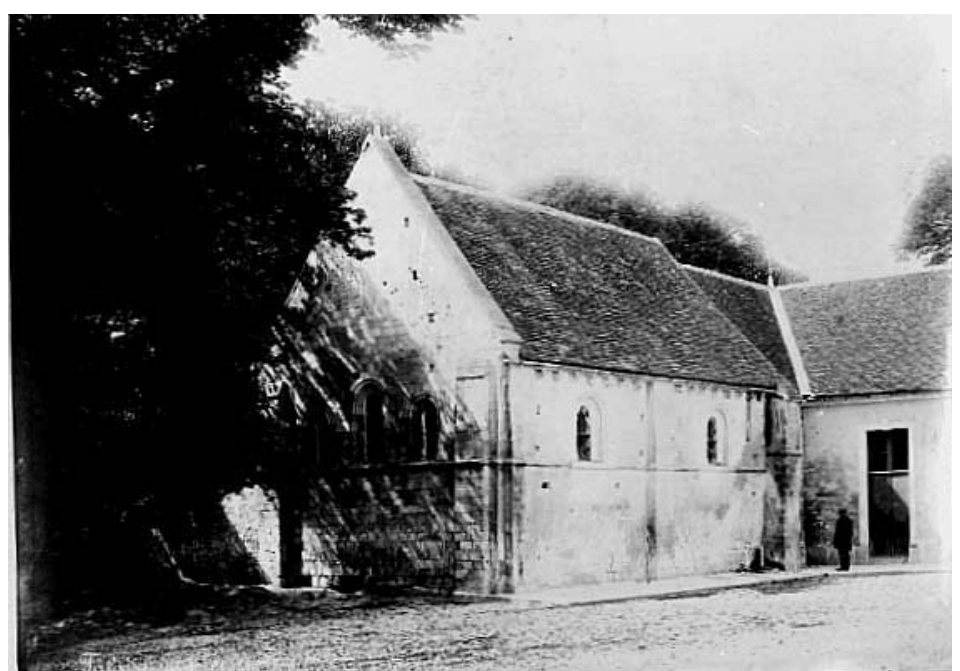

Fig. 5 : Vue de la chapelle Saint-Nicolas, 1892 [BRAQUEHAIS, 1895] (Cliché de P. Corbierre, Inventaire général - ADAGP).
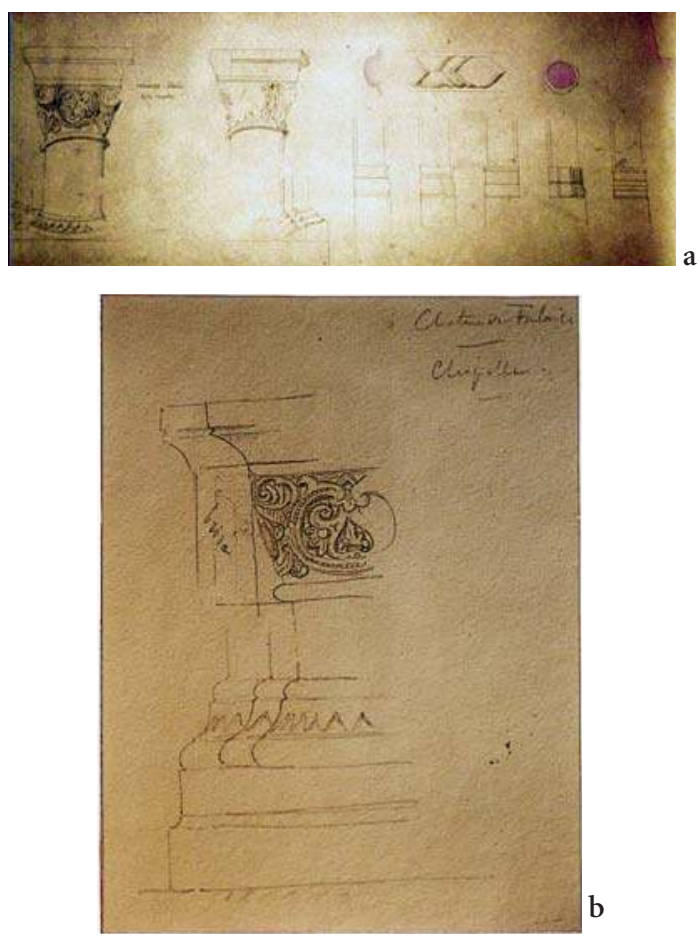

Fig. 6 (a et b) : Détails des vestiges décoratifs du chœur de la chapelle castrale. Dessins à l'encre de Chine sur papier, par Danjoy, [1891]. Éch. 0,01. Paris, Méd. du Patrimoine, Archives de la Commission des Monuments historiques, 511. 


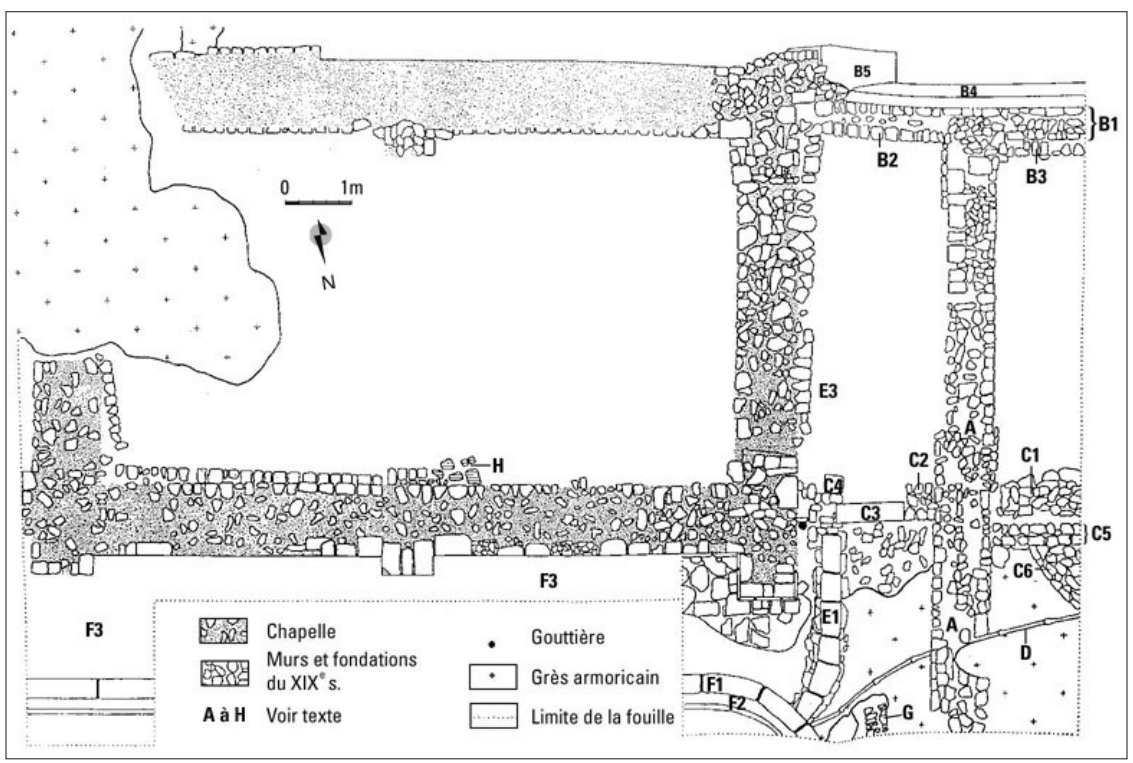

Fig. 7 : Relevé cartographique du sondage archéologique de 1986, par P. Couanon; vues de la chapelle en cours de dégagement (vue ouest, contrefort de l'angle nord-ouest) [COUANON, 1986, p. 79 et 88].

Légende des repères $\mathrm{A}$ à $\mathrm{F} 3$

A Mur composé essentiellement de blocs taillés de récupération et de moellons calcaires pour les parements, de pierres calcaires de différents modules pour le blocage (larg. $0,80 \mathrm{~m}$ x haut. 0,20 à $0,50 \mathrm{~m}$ ). L'ensemble est lié par un mortier de chaux et de sable. Le mur se prolonge au-delà de la limite du sondage vers le nord.

B1 Mur de même composition que A (larg. 0,80 m), semble couper ou s'appuyer sur B2.

B2 Mur de même composition que A (larg. 0,50 m), avec moins de mortier.

B3 Plaquage de briques rouges sur la face interne de B1, reposant sur une fondation de pierres calcaires. A ce niveau, sans doute, le sol d'occupation d'une dépendance du collège.

B4 Enduit de ciment (épais. 0,10 à 0,30 m) appliqué sur les faces externes de B1 et B2.

B5 Contrefort de ciment gris consolidant l'angle du chœur. Les murs A, B1, B3, B4 et B5 sont ceux d'une dépendance du collège construite au XIXe s., qui a entamé l'arasement de $\mathrm{C} 1, \mathrm{C} 5$ et $\mathrm{C} 6$, séparé $\mathrm{C} 4$ de $\mathrm{C} 2$ et coupé B2.

C1, C2, C4 Mur est-ouest dans le prolongement du mur nord du chœur (larg. 0,50 m), de même composition que B2. Le mur C1 a conservé une assise de pierres de parement; $\mathrm{C} 2$ et $\mathrm{C} 4$ sont arasés au niveau des fondations (larg. 0,60 m).

C3 Parallélépipède rectangle de granite gris $(1,30 \times 0,30 \mathrm{~m})$, parfaitement taillé. L'arête nord usée révèle sans doute une marche, qui peut correspondre à une porte dont les piédroits reposaient sur $\mathrm{C} 2$ et $\mathrm{C} 4$.

C5 Doublement du mur C1 (larg. 0,40 m), de même composition, lié par un mortier plus jaune.

C6 Fondation en pierres calcaires sans liant, dessinant au nord un début d'arc-de-cercle.

$\mathrm{D}$ Tuyau de fonte, à plusieurs éléments emboîtés, reposant sur la roche, installé grâce à une brèche dans le mur $\mathrm{A}$. 
E1 Canal d'évacuation des eaux du caniveau F2, fait de blocs de pierres calcaires, recouverts de dalles. Un enduit de mortier recouvre l'intérieur. Tranchée coupée partiellement par un dépôt sableux.

E2 Base de gouttière en fonte, les eaux se déversant dans E1.

E3 Tranchée de drainage dans le sol recueillant les eaux de $\mathrm{C} 1$ et $\mathrm{C} 2$. Elle longe le mur ouest du chœur en détruisant les niveaux sur une profondeur de plus de 0,80 m. Le pilier nord-ouest est détruit partiellement par les structures E1 et E2; la structure E3 a détruit les deux contreforts.

F1 Bordure de trottoir de la cour, en blocs de granite.

F2 Caniveau.

F3 Trottoir en béton. . 


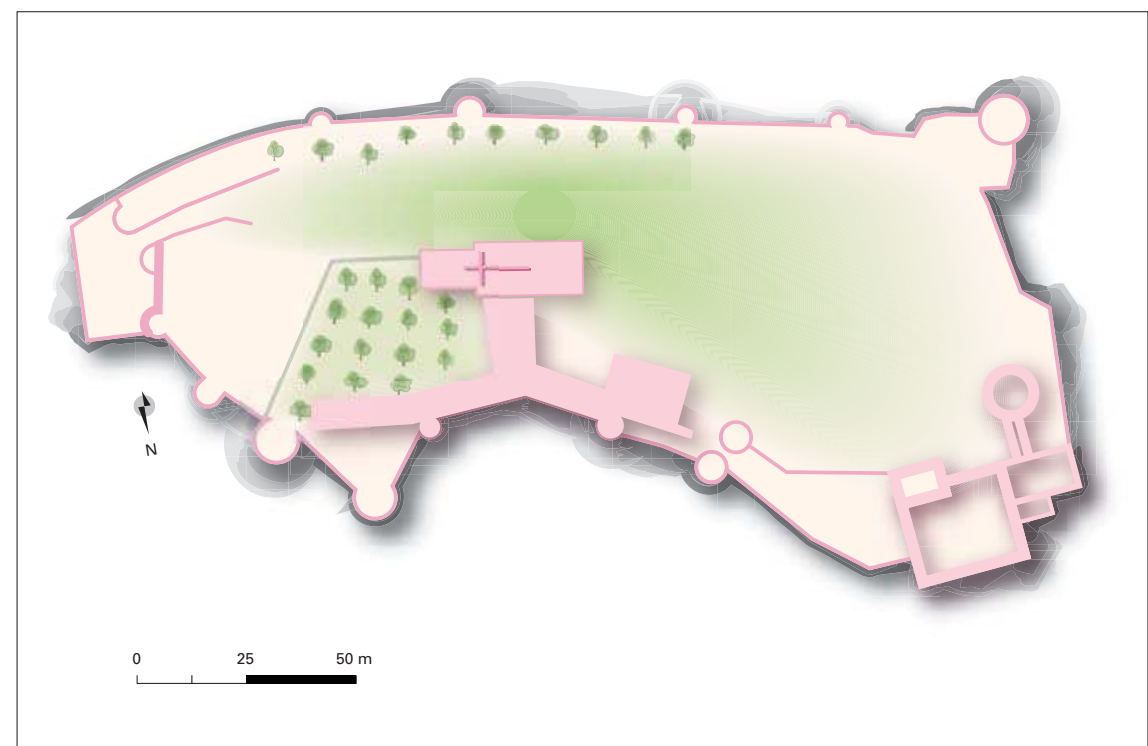

Fig. 8: La chapelle Saint-Nicolas: plan au sol et situation dans l'espace castral au milieu du XVIII ${ }^{e}$ siècle (restitution).

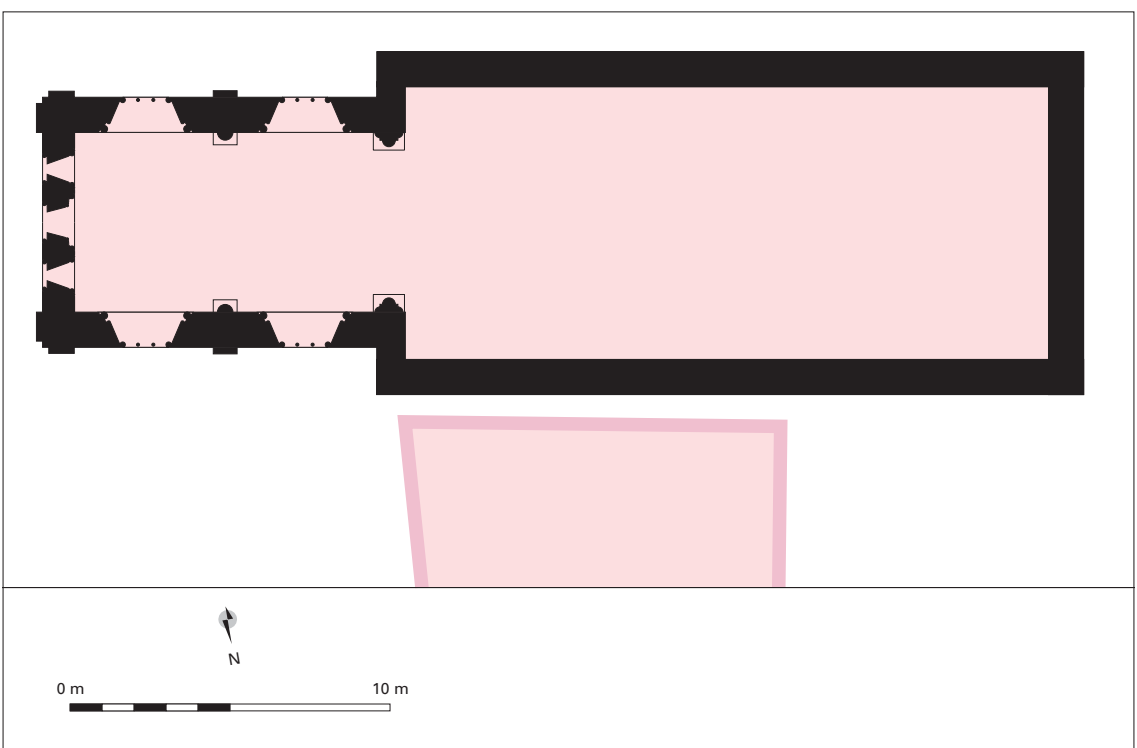

Fig. 8a: Reconstitution de l'évolution architecturale de la chapelle castrale de Falaise d'après des plans de l'époque moderne et du XIX ${ }^{\mathrm{e}}$ siècle: 1744-1747 (Arch. nat., F $\mathrm{F}^{14}$ 8451, fol. 28). 


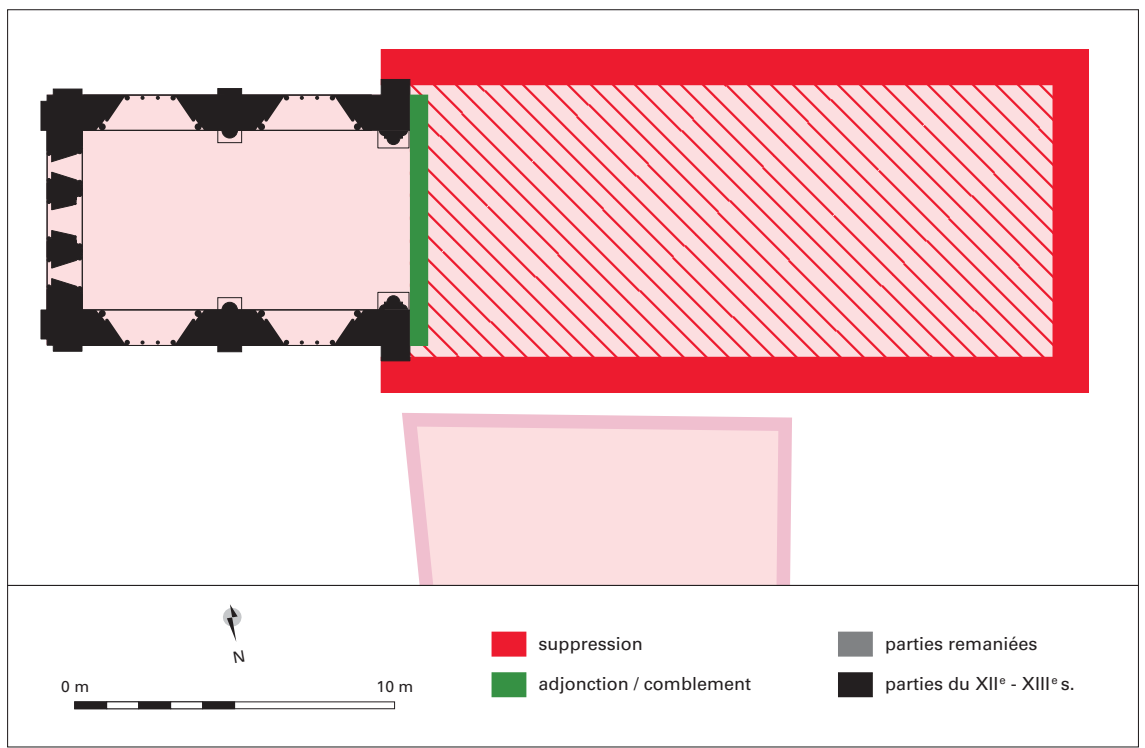

Fig. 8b : Reconstitution de l'évolution architecturale de la chapelle castrale de Falaise d'après des plans de l'époque moderne et du XIX ${ }^{e}$ siècle : 1792 (Caen, Arch. dép. Calvados, 386 E dépôt 499).

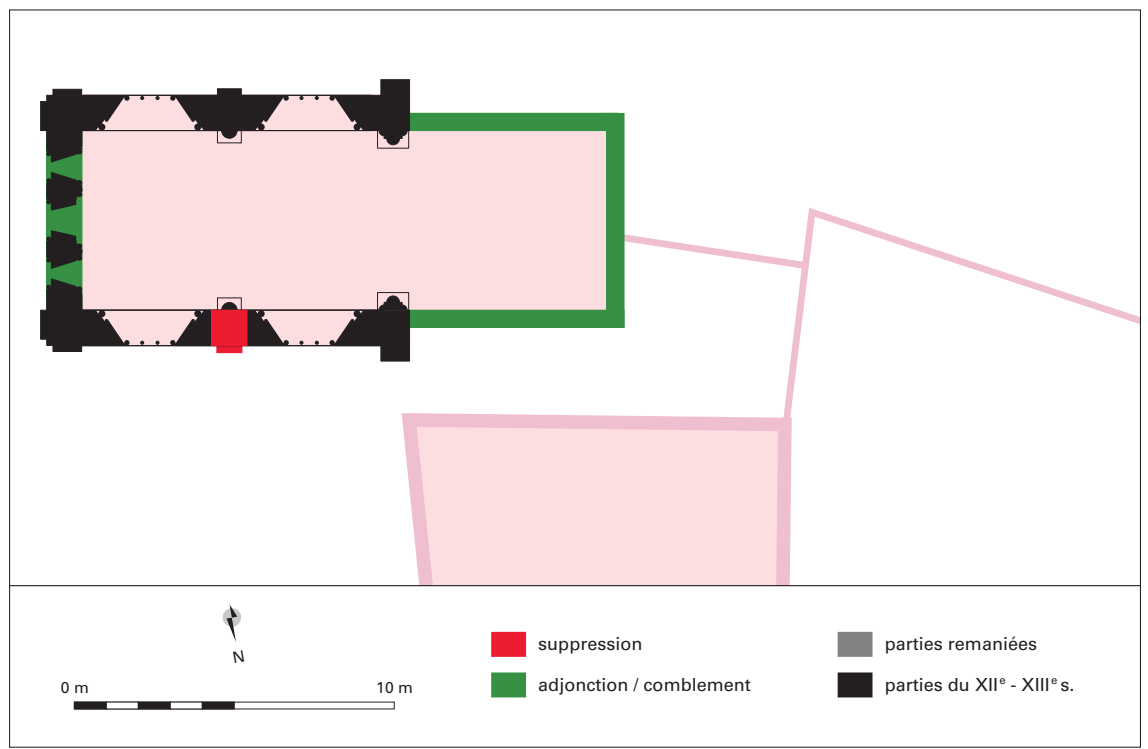

Fig. 8c: Reconstitution de l'évolution architecturale de la chapelle castrale de Falaise d'après des plans de l'époque moderne et du XIX ${ }^{e}$ siècle: 1829 (Caen, Arch. dép. Calvados, plan cadastral Falaise 1829). 


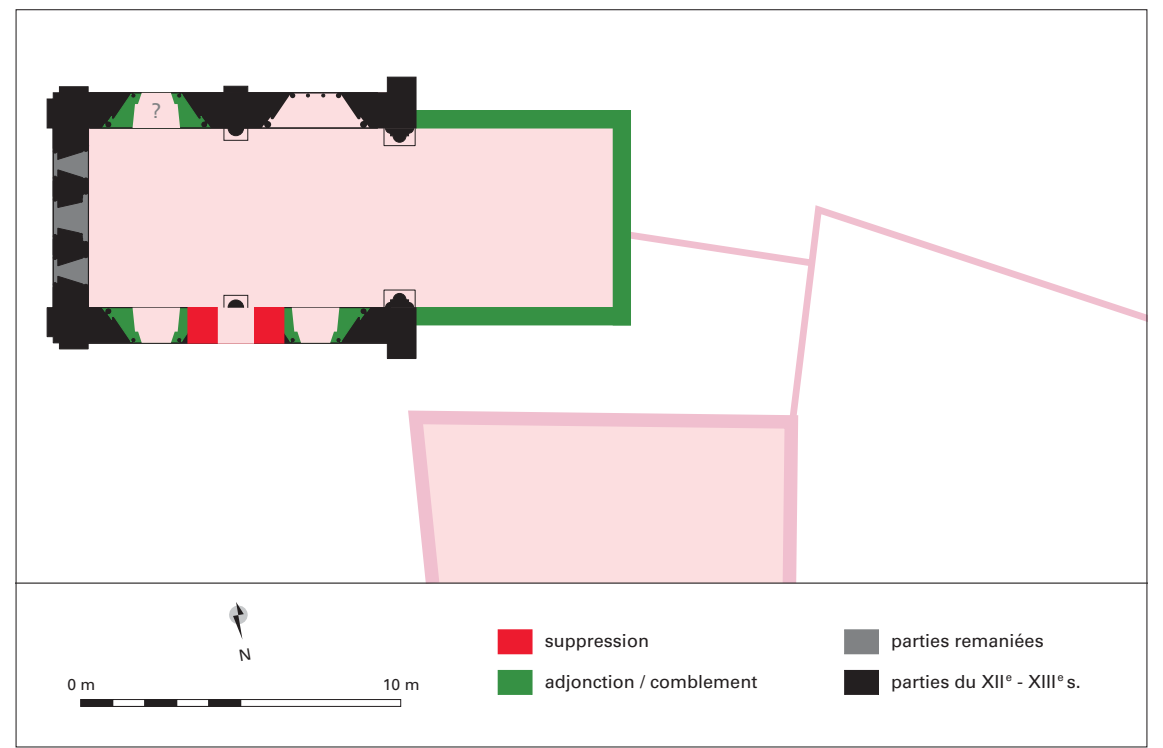

Fig. 8d: Reconstitution de l'évolution architecturale de la chapelle castrale de Falaise d'après des plans de l'époque moderne et du XIX siècle : 1836 (Caen, Bibl. mun., FN E 850 et L 285).

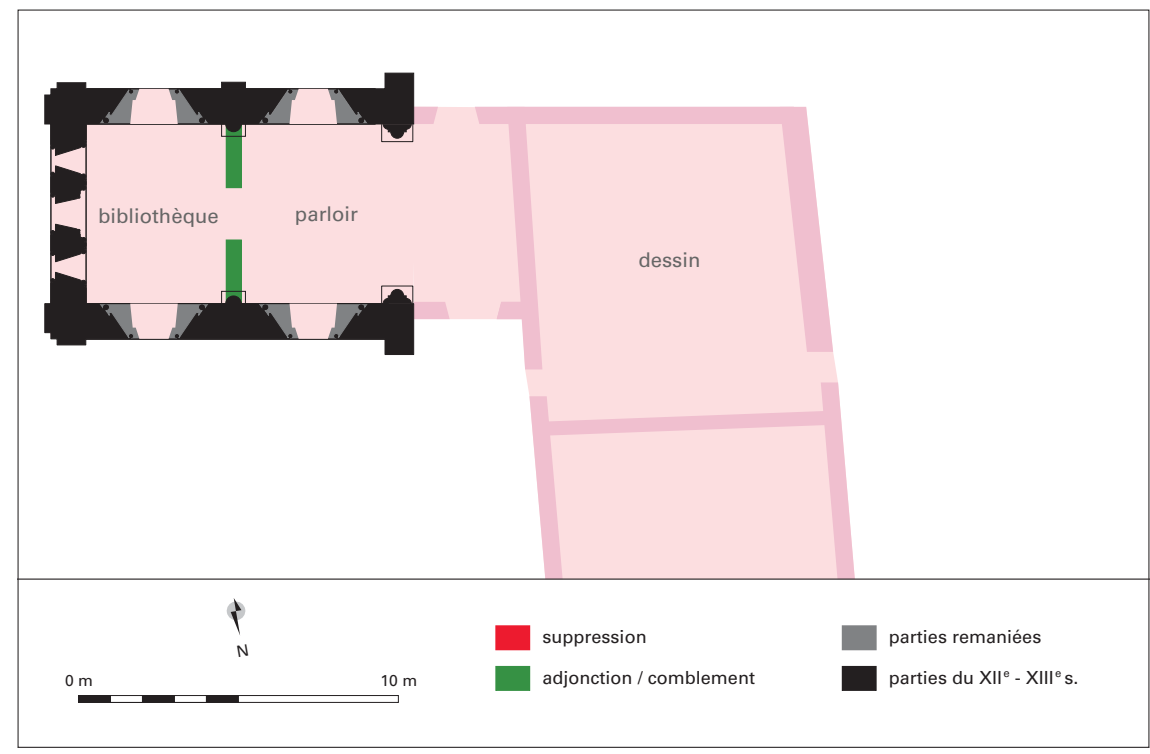

Fig. 8e: Reconstitution de l'évolution architecturale de la chapelle castrale de Falaise d'après des plans de l'époque moderne et du XIX' siècle: 1881 (Caen, Arch. dép. Calvados, 386 E dépôt 491). 


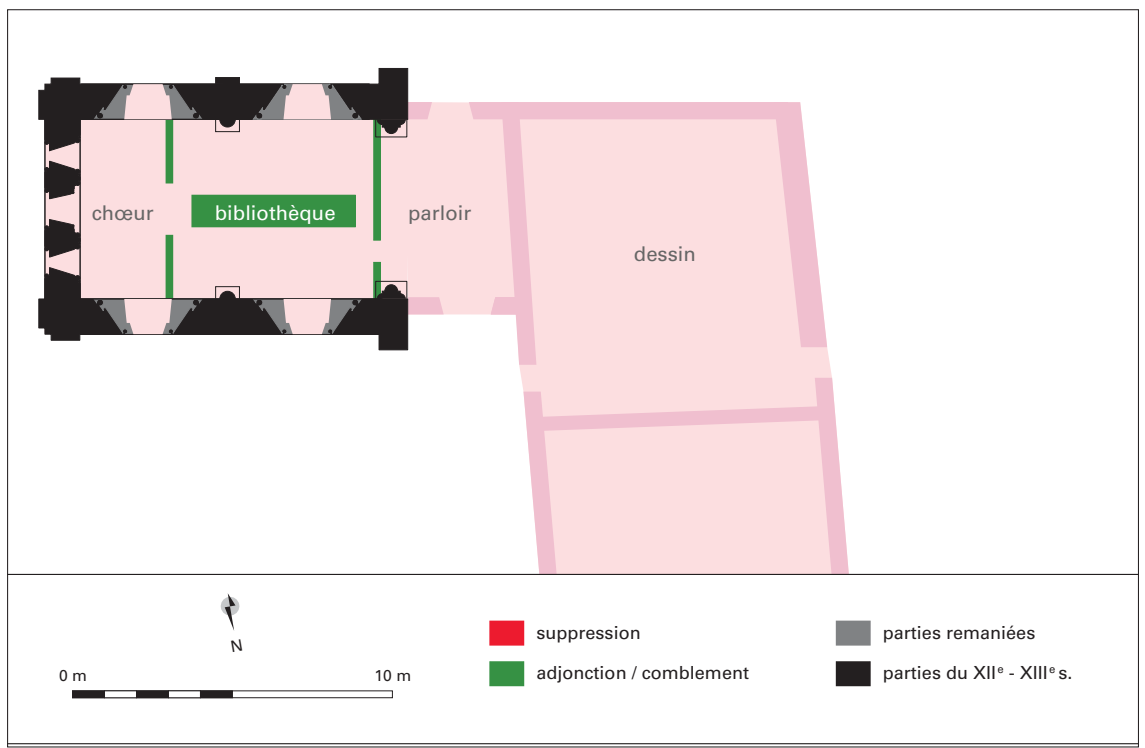

Fig. 8f: Reconstitution de l'évolution architecturale de la chapelle castrale de Falaise d'après des plans de l'époque moderne et du XIX'e siècle : 1885 (Caen, Arch. dép. Calvados, 386 E dépôt 493).

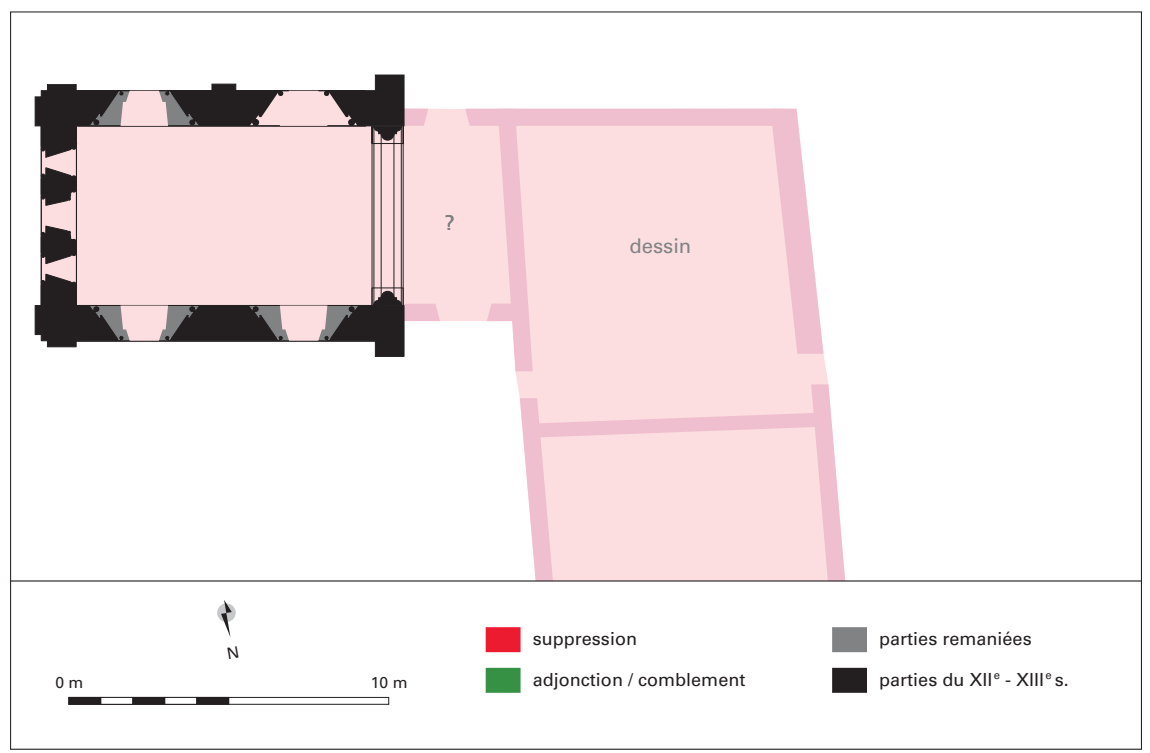

Fig. 8g: Reconstitution de l'évolution architecturale de la chapelle castrale de Falaise d'après des plans de l'époque moderne et du XIX siècle: 1891 (Paris, Méd. du Patrimoine, plan 507). 